\title{
SIMULATION ANALYSIS OF A DAMAGED 9-STORY SRC BUILDING DURING THE 2011 GREAT EAST JAPAN EARTHQUAKE
}

\author{
Miao $\mathrm{CAO}^{1}$, Masato MOTOSAKA ${ }^{2}$, Tsoggerl TSAMBA ${ }^{3}$ and Kazushi YOSHIDA ${ }^{4}$ \\ ${ }^{1}$ Student Member of JAEE, Graduate Student, Department of Architecture and Building Science, \\ Tohoku University, Sendai, Miyagi, Japan, caomiao@saigai.str.archi.tohoku.ac.jp \\ ${ }^{2}$ Member of JAEE, Professor, International Research Institute of Disaster Science, \\ Tohoku University, Sendai, Miyagi, Japan, motosaka@irides.tohoku.ac.jp \\ ${ }^{3}$ Student Member of JAEE, Graduate Student, Department of Architecture and Building Science, \\ Tohoku University, Sendai, Miyagi, Japan, tsoggerel@hjogi.pln.archi.tohoku.ac.jp \\ ${ }^{4}$ Graduate Student, Department of Architecture and Building Science, \\ Tohoku University, Sendai, Miyagi, Japan, k-yoshida@hjogi.pln.archi.tohoku.ac.jp
}

\begin{abstract}
A 9-story steel frame reinforced concrete building in Sendai was severely damaged during the 2011 Great East Japan Earthquake. Fortunately, two seismometers were emplaced at the $1^{\text {st }}$ floor and the $9^{\text {th }}$ floor, and the whole earthquake records were observed during this earthquake. The nonlinear response analysis of the building is simulated which based on the elastic plastic properties of constituent structural elements during the earthquake. And a partial uplift phenomenon between the $2^{\text {nd }}$ floor and the $3^{\text {rd }}$ floor which observed is confirmed by the simulation analysis.
\end{abstract}

Key Words: simulation, nonlinear response, elastic plastic, stiffness reduction, damaged SRC building, 2011 Great East Japan Earthquake

\section{INTRODUCTION}

A 9-story steel frame reinforced concrete building which be used as the Research Building of Civil Engineering and Architecture in Tohoku University, Sendai was severely damaged during the 2011 Great East Japan Earthquake ${ }^{1)}$. This building was completed in 1969 and has experienced several strong earthquake motions such as the 1978 Miyagi Earthquake, the 2005 Miyagi Earthquake, the 2008 Iwate-Miyagi Nairiku Earthquake and etc. In 2000, the building was retrofitted. Main points of the seismic retrofitting are the brace reinforcements, the floor slab reinforcements, and the plate reinforcements for beams.

Two seismometers were emplaced at the $1^{\text {st }}$ floor and the $9^{\text {th }}$ floor since the building built and a new SHM system with 3 seismometers (emplaced at the $1^{\text {st }}, 5^{\text {th }}$ and $9^{\text {th }}$ floor) was installed in 2007. In this earthquake, the whole earthquake records at the $1^{\text {st }}$ floor and the $9^{\text {th }}$ floor were observed. The nonlinear response analysis of the building is simulated which based on the elastic plastic properties of constituent structural elements. 


\section{GENERAL SITUATION OF BUILDING}

\section{Structure Condition}

The investigated building on Aobayama Hill in the west of Sendai City is shown in Fig. $1^{2), 3)}$. This building which completed in March 1969 has been used as the research building of the Department of Civil Engineering and Architecture and has been existed for 43 years.
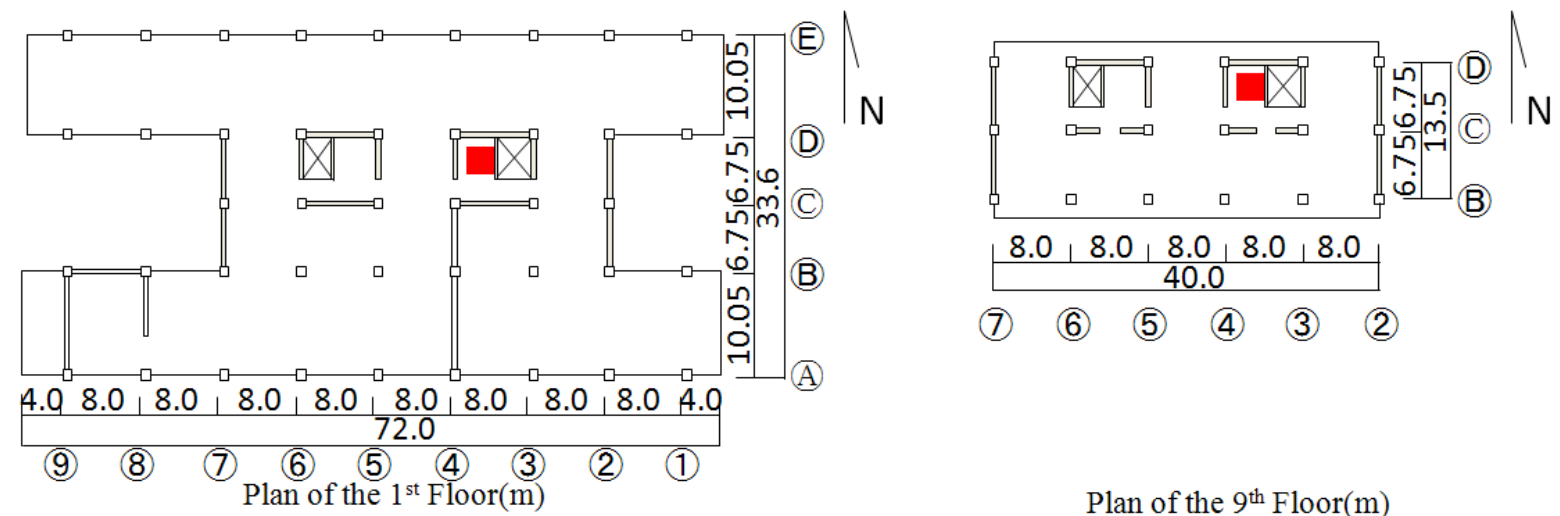

(7) (6) (5) (4) (3) (2)

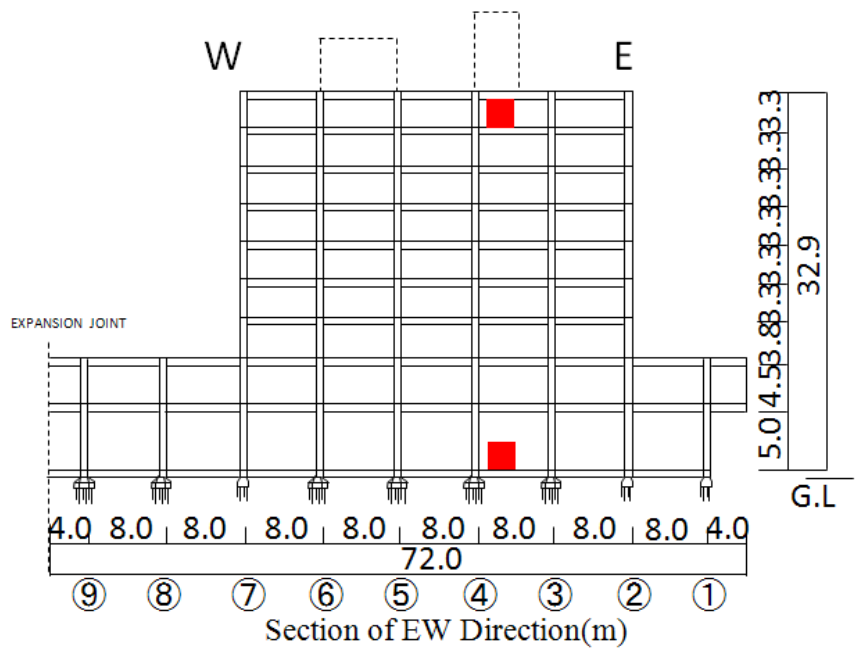

Plan of the $9^{\text {th }}$ Floor $(m)$

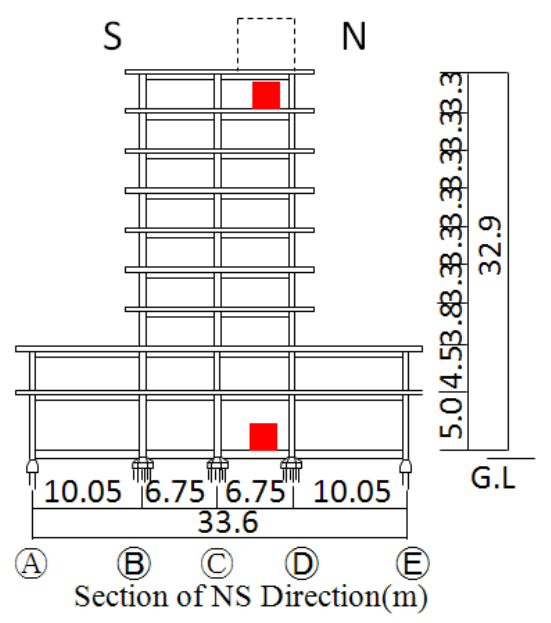

Fig. 1 Plan and Section of the Building

This building is divided into two parts by expansion joint. The high part is a SRC structure which composed of a 2 -story low structure $(72 \times 33.6 \mathrm{~m})$ and a 9 -story high structure $(40 \times 13.5 \mathrm{~m})$. The RC walls such as retaining walls and smoke barriers are extremely few. There are six pieces of shear walls in the span direction ( 2 pieces in the core part, 4 pieces in the gable part) and four pieces of shear walls in the ridge direction ( 2 pieces in the core part, 2 pieces in the gable part). As shear walls which in the core part are in the north side of the structure, twisting vibration can be observed. The cross pile $(\Phi=50 \mathrm{~cm}, \mathrm{~L}=12 \mathrm{~m})$ isolated foundation is used as well. Two seismometers were emplaced at the $1^{\text {st }}$ floor and the $9^{\text {th }}$ floor. The locations of seismometers are plotted in Fig. 1. The predominant period by micro tremor observations are shown in Table 1.

This building was retrofitted in 2000 because it had experienced several strong earthquakes. Main points of the seismic retrofitting are the brace reinforcements, the floor slab reinforcements, and the plate reinforcements for beams. The position of elements (color for reinforcements) is shown in Fig. 2.

The materials of construction are shown in Table 2. The lists of the section for main elements are shown in Appendix and the width of shear walls and the weight of floors are shown in Table 3. 
Table 1 Predominant Period of Structure

\begin{tabular}{|l|c|c|c|c|}
\hline \multirow{2}{*}{ Time } & \multicolumn{3}{|c|}{ Predominant Period by Micro Tremor Observations } \\
\cline { 2 - 5 } & \multicolumn{2}{|c|}{ NS Direction } & \multicolumn{2}{c|}{ EW Direction } \\
\cline { 2 - 5 } & Period (sec) & Frequency $(\mathrm{Hz})$ & Period (sec) & Frequency $(\mathrm{Hz})$ \\
\hline 1969 & 0.44 & 2.28 & 0.41 & 2.54 \\
\hline 2000.07 & 0.68 & 1.48 & 0.65 & 1.54 \\
\hline 2001.05 & 0.59 & 1.74 & 0.54 & 1.85 \\
\hline 2011.03 .19 & 0.86 & 1.17 & 0.73 & 1.37 \\
\hline
\end{tabular}

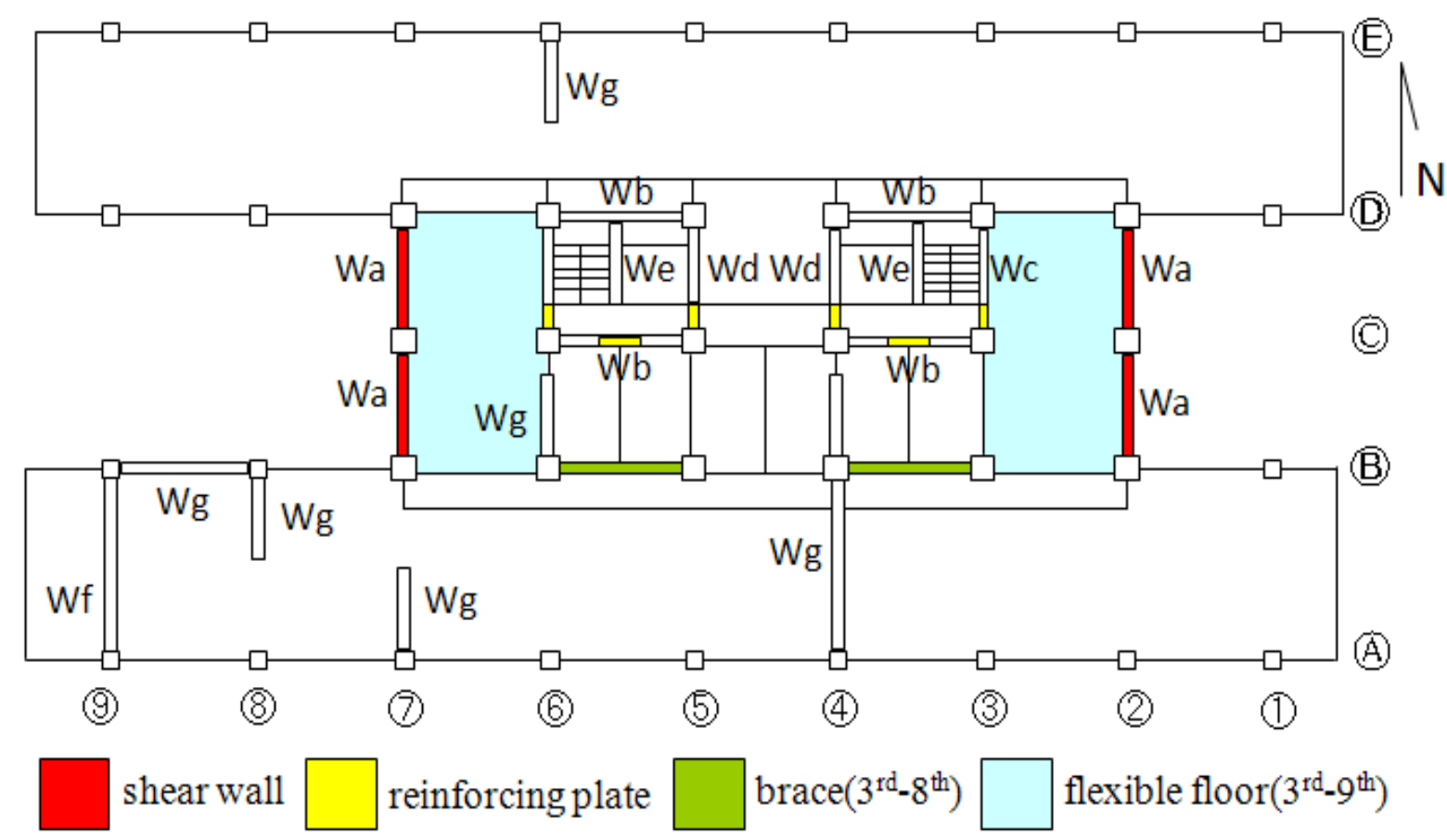

Fig. 2 Position of Elements

Table 2 Materials of Construction

\begin{tabular}{|c|c|}
\hline Material & Strength \\
\hline \multirow{2}{*}{ Concrete } & Fc210(Foundation,Foundation Beam) \\
\cline { 2 - 2 } Steel & Fc180(Other) \\
\hline \multirow{2}{*}{ Rebar } & SS41 \\
\cline { 2 - 2 } & SD35(Welding) \\
\hline \multirow{2}{*}{ Pile } & $(\Phi=50 \mathrm{~cm}, \mathrm{~L}=12 \mathrm{~m})$ \\
\cline { 2 - 2 } & \\
\hline
\end{tabular}


Table 3 Width of Shear Wall and Weight of Floor

\begin{tabular}{|c|c|c|c|c|c|c|c|c|}
\hline Floor & $\mathrm{Wa}(\mathrm{mm})$ & $\mathrm{Wb}(\mathrm{mm})$ & $\mathrm{Wc}(\mathrm{mm})$ & $\mathrm{Wd}(\mathrm{mm})$ & $\mathrm{We}(\mathrm{mm})$ & $\mathrm{Wf}(\mathrm{mm})$ & $\mathrm{Wg}(\mathrm{mm})$ & Weight $(\mathrm{kN})$ \\
\hline $\mathrm{RF}$ & & & & & & & & 6985 \\
\hline $9 \mathrm{~F}$ & 180 & 150 & 200 & 150 & 200 & & & 8299 \\
\hline $8 \mathrm{~F}$ & 180 & 150 & 200 & 150 & 200 & & & 8339 \\
\hline $7 \mathrm{~F}$ & 180 & 200 & 200 & 150 & 200 & & & 8378 \\
\hline $6 \mathrm{~F}$ & 180 & 200 & 200 & 150 & 200 & & & 8515 \\
\hline $5 \mathrm{~F}$ & 200 & 300 & 200 & 200 & 200 & & & 8652 \\
\hline $4 \mathrm{~F}$ & 200 & 300 & 200 & 200 & 200 & & & 9261 \\
\hline $3 \mathrm{~F}$ & 250 & 300 & 250 & 250 & 200 & & & 27468 \\
\hline $2 \mathrm{~F}$ & 300 & 400 & 300 & 300 & 200 & & 150 & 29665 \\
\hline $1 \mathrm{~F}$ & 400 & 500 & 400 & 400 & 200 & 250 & 150 & 58860 \\
\hline
\end{tabular}

\section{Ground Condition}

The ground condition around the building is shown in Fig. 3. There is cut soil in the west side and fill soil in the east side. The clay layer $(\mathrm{N}<10)$ is in the upper part which above $3 \mathrm{~m}$, the silt layer $(14<\mathrm{N}<30)$ is between $3-10 \mathrm{~m}$, and the loam layer $(30<\mathrm{N}<50)$ is in the lower part.

Furthermore, the value of $\mathrm{N}$ in the west side is above 50 and the value of $\mathrm{N}$ in the east side is about 30 in the depth $12 \mathrm{~m}$ which piles fixed.

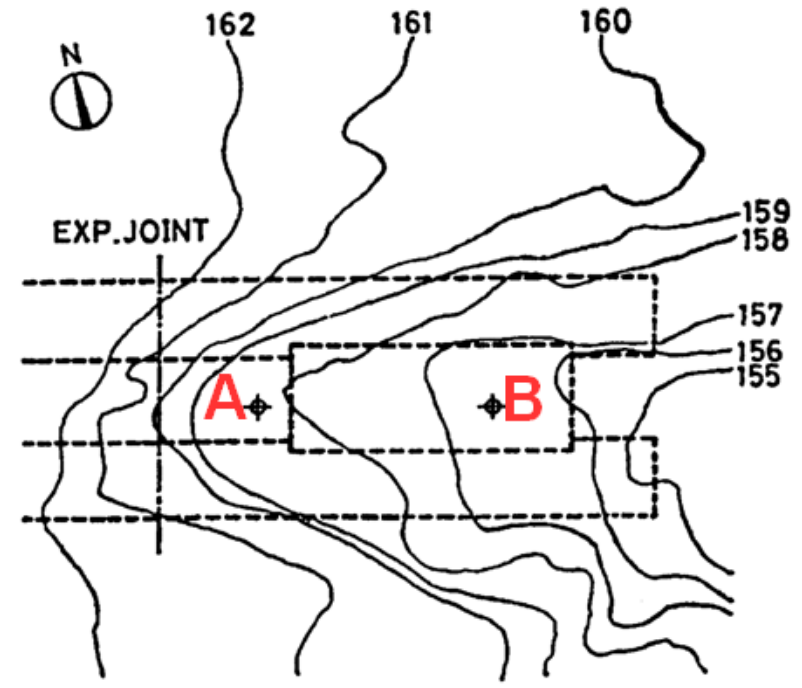

Point A

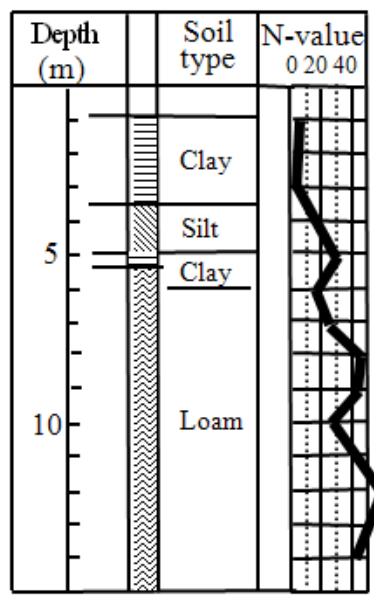

Point B

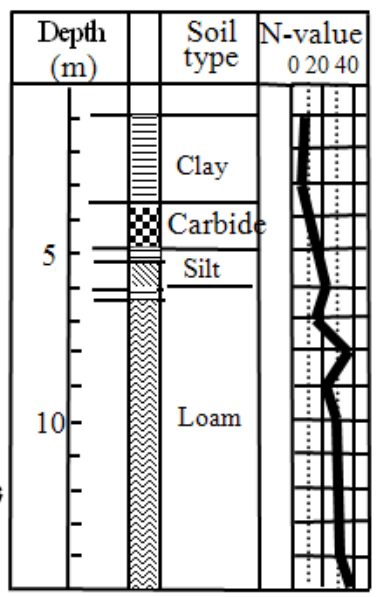

Fig. 3 Ground Condition

\section{Stiffness Reduction}

As the building had experienced several strong earthquakes and retrofitted in 2000 , the performance of the building and the stiffness of constituent structural elements are subject to change. Therefore, the stiffness reduction is important to the simulation analysis. The stiffness reduction of each element was investigated in 2000 and $2002^{4)}$. The stiffness reduction factors are divided into several domains as shown in Fig. $4^{5), 6)}$. 

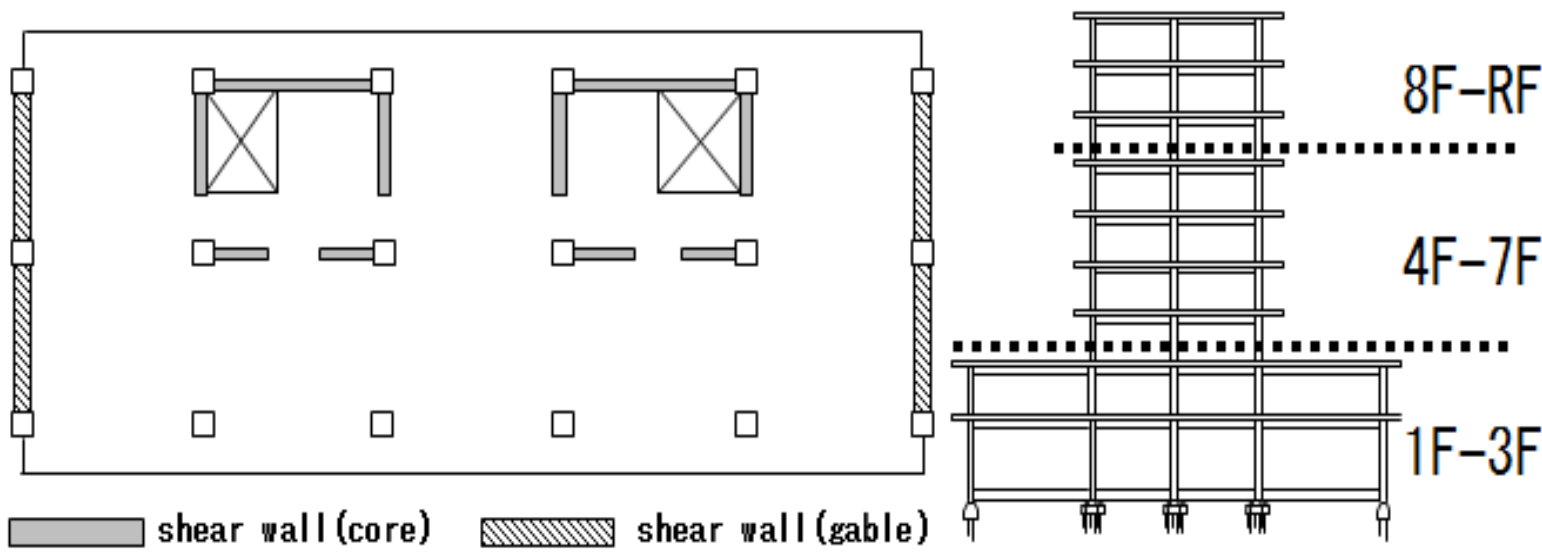

Fig. 4 Division of Constituent Structural Elements

The stiffness reduction factors were identified by vibration test and the results are shown in Table 4 . The evaluation function of indention is shown in equation 1 and the Levenberg-Marquardt algorithm is used to solve this problem.

$$
E=\sum_{n=1}^{m} \sum_{f=0.5}^{10}(G(f)-H(f))^{*}(G(f)-H(f))
$$

Where, $\mathrm{m}$ is the number of observation points in vibration test, $\mathrm{f}$ is the frequency domain from $0.5 \mathrm{~Hz}$ to $10 \mathrm{~Hz}, \mathrm{G}$ is the analysis data and $\mathrm{H}$ is the resonance curve and the phase curve.

The stiffness reduction factors (ratio of the new stiffness to the former stiffness) are used to set the initial stiffness in simulation.

Table 4 Stiffness Reduction Factor

\begin{tabular}{|c|c|c|c|c|c|c|}
\hline \multirow{2}{*}{ Floor } & \multicolumn{2}{|c|}{ Beam \& Column } & \multicolumn{2}{c|}{ Shear Wall(core) } & \multicolumn{2}{c|}{ Shear Wall(gable) } \\
\cline { 2 - 7 } & EW & NS & \multicolumn{2}{|c|}{ EW } & NS & \multicolumn{2}{c|}{ E } & W \\
\hline RF & 0.48 & 0.59 & \multicolumn{2}{|c|}{} \\
\hline 9F & 0.48 & 0.59 & 0.42 & 0.55 & 0.79 & 0.79 \\
\hline 8F & 0.48 & 0.59 & 0.42 & 0.55 & 0.79 & 0.79 \\
\hline 7F & 0.48 & 0.59 & 0.42 & 0.55 & 0.79 & 0.79 \\
\hline 6F & 0.35 & 0.59 & 0.41 & 0.49 & 0.78 & 0.77 \\
\hline 5F & 0.35 & 0.59 & 0.41 & 0.49 & 0.78 & 0.77 \\
\hline 4F & 0.35 & 0.59 & 0.41 & 0.49 & 0.78 & 0.77 \\
\hline 3F & 0.35 & 0.59 & 0.41 & 0.49 & 0.78 & 0.77 \\
\hline 2F & 0.62 & 0.61 & 0.68 & 0.61 & 0.74 & 0.72 \\
\hline 1F & 0.62 & 0.61 & 0.68 & 0.61 & 0.74 & 0.72 \\
\hline
\end{tabular}

\section{STRONG MOTION AND BUILDING DAMAGE}

\section{Strong Motion Records}

This building has experienced several strong earthquake motions such as the 1978 Miyagi Earthquake, the 2005 Miyagi Earthquake, the 2008 Iwate-Miyagi Nairiku Earthquake and etc. In this earthquake, the seismometer that emplaced at the $5^{\text {th }}$ floor did not work because of a power failure, but the others emplaced at the $1^{\text {st }}$ floor and the $9^{\text {th }}$ floor worked normally. The whole earthquake records at the $1^{\text {st }}$ floor and the $9^{\text {th }}$ floor were observed shown in Fig. 5. 

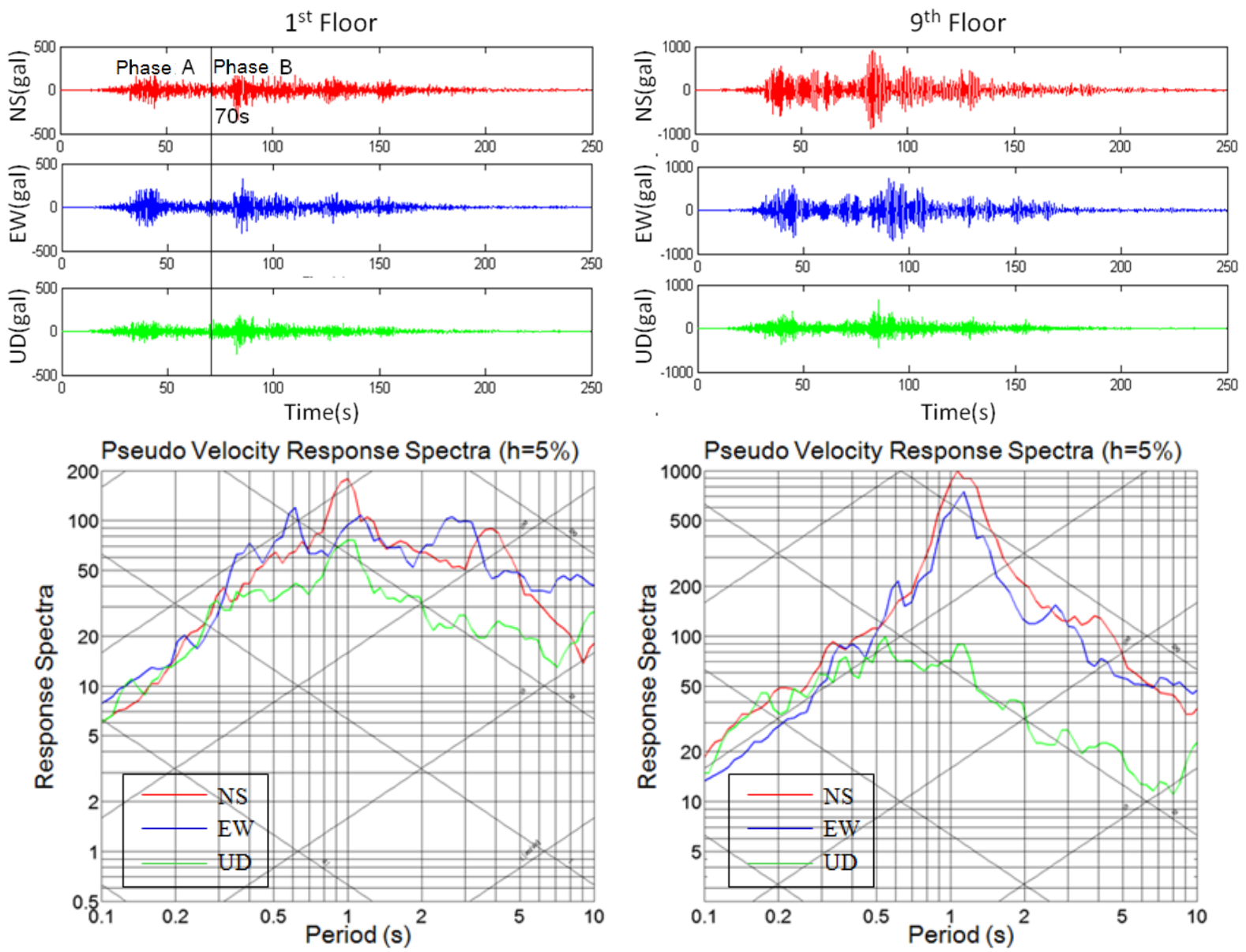

Fig. 5 Earthquake Records of the 2011 Great East Japan Earthquake

Two peaks are observed from the earthquake records. The first peak is around 40 s and the second one is around 80s. Dividing the records into two phases as shown in Fig. 5, the characteristics are different. The pseudo velocity response spectral ratios $\left(9^{\text {th }}\right.$ floor $/ 1^{\text {st }}$ floor $)$ are shown in Fig. 6.
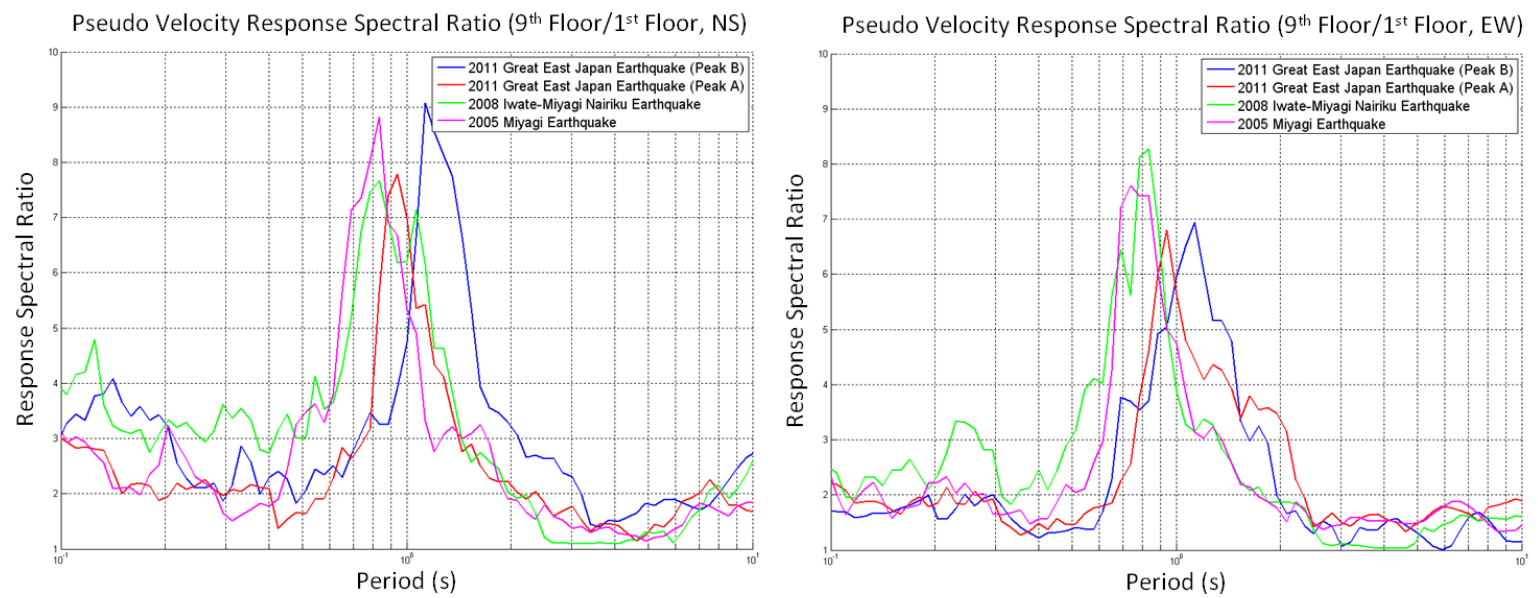

Fig. 6 Pseudo Velocity Response Spectral Ratio $\left(9^{\text {th }}\right.$ Floor $/ 1^{\text {st }}$ Floor $)$ 
The predominant period moved from short period to long period as shown in Fig. 6. That means the stiffness of the building reduced in several earthquakes. Concretely speaking, the predominant period did almost no change in the NS direction and changed less than $0.1 \mathrm{~s}$ in the EW direction between the 2005 Miyagi Earthquake and the 2008 Iwate-Miyagi Nairiku Earthquake. It was considered as rarely damage caused by these two earthquakes. But in the 2011 Great East Japan Earthquake, the shifts of predominant period that larger than $0.1 \mathrm{~s}$ are obviously observed in the both directions. Comparatively, it was considered that the building was damaged in the earthquake and the main damage might be caused after Phase A.

\section{Building Damage}

This building was severely damaged in the 2011 Great East Japan Earthquake. Columns, beams and walls failed even all over the building from the $1^{\text {st }}$ floor to the $9^{\text {th }}$ floor. The crack positions were investigated after the earthquake. The crack pattern of the building is shown in Fig. 7. The damage of the east part of the building is more severe than the west one, which might be caused by the difference of ground condition that fill soil in the east side and cut soil in the west side.

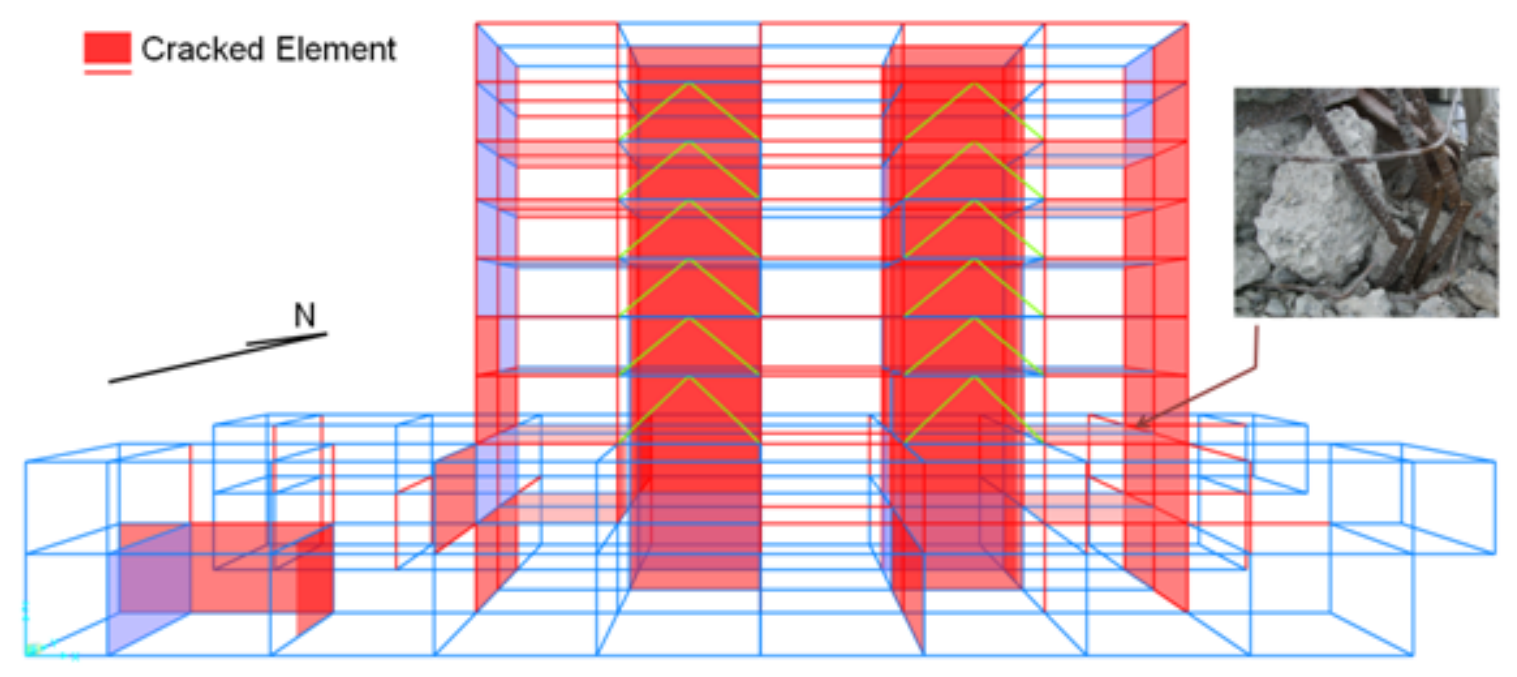

Fig. 7 Crack Pattern of the Building

\section{SIMULATION ANALYSIS OF BUILDING}

\section{Element Model ${ }^{7), 8)}$}

The analytic models of the constituent structural elements are shown in the following section. The element model is shown in Fig. 8. Element model for column is defined as a line element with nonlinear bending springs at both ends and two nonlinear shear springs in the middle of the element in $\mathrm{Y}$ and $\mathrm{Z}$ directions. Element model for wall is defined as a line element with nonlinear bending springs at both ends and three nonlinear shear springs. One is in the middle of the wall panel and others are in the side columns.

The elastic element, nonlinear bending springs and nonlinear shear springs are considered in the model as the equation 2 . The displacement vector of the elastic element, the nonlinear bending springs and the nonlinear shear springs are shown as equation 3 to 11 . 


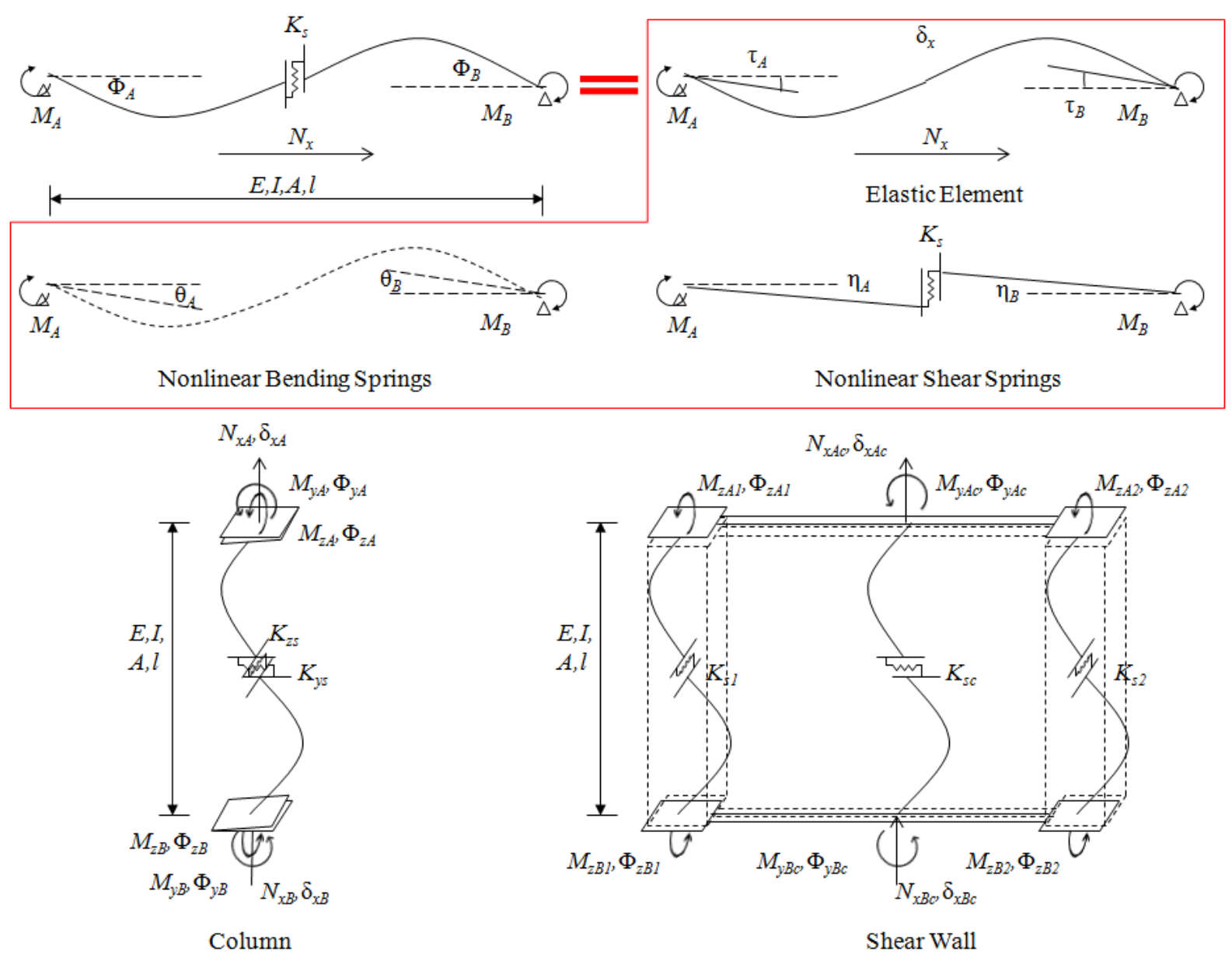

Fig. 8 Element Model

$$
\left\{\begin{array}{c}
\Phi_{\mathrm{A}} \\
\Phi_{\mathrm{B}} \\
\delta_{\mathrm{x}}
\end{array}\right\}=\left\{\begin{array}{c}
\tau_{\mathrm{A}} \\
\tau_{\mathrm{B}} \\
\delta_{\mathrm{x}}
\end{array}\right\}+\left\{\begin{array}{c}
\theta_{\mathrm{A}} \\
\theta_{\mathrm{B}} \\
0
\end{array}\right\}+\left\{\begin{array}{c}
\eta_{\mathrm{A}} \\
\eta_{\mathrm{B}} \\
0
\end{array}\right\}
$$

Beam:

$$
\begin{aligned}
& \left\{\begin{array}{l}
\tau_{\mathrm{A}} \\
\tau_{\mathrm{B}} \\
\delta_{\mathrm{x}}
\end{array}\right\}=\left[\begin{array}{ccc}
l / 3 E I & -l / 6 E I & 0 \\
-l / 6 E I & l / 3 E I & 0 \\
0 & 0 & l / E A
\end{array}\right]\left\{\begin{array}{l}
M_{A} \\
M_{B} \\
N_{x}
\end{array}\right\} \\
& \left\{\begin{array}{l}
\theta_{\mathrm{A}} \\
\theta_{\mathrm{B}}
\end{array}\right\}=\left[\begin{array}{cc}
f_{A} & 0 \\
0 & f_{B}
\end{array}\right]\left\{\begin{array}{l}
M_{A} \\
M_{B}
\end{array}\right\}
\end{aligned}
$$

Where, $f_{A}$ and $f_{B}$ are the flexural stiffness of nonlinear bending springs at both ends of the element.

$$
\left\{\begin{array}{c}
\eta_{A} \\
\eta_{B}
\end{array}\right\}=\left[\begin{array}{ll}
1 / K_{S} l & 1 / K_{S} l \\
1 / K_{S} l & 1 / K_{S} l
\end{array}\right]\left\{\begin{array}{l}
M_{A} \\
M_{B}
\end{array}\right\}
$$

Where, $k_{s}$ is the shear stiffness of the nonlinear shear spring. 
Column:

$$
\begin{aligned}
\left\{\begin{array}{l}
\tau_{\mathrm{A}} \\
\tau_{\mathrm{B}}
\end{array}\right\} & =\left[\begin{array}{cc}
l / 3 E I & -l / 6 E I \\
-l / 6 E I & l / 3 E I
\end{array}\right]\left\{\begin{array}{l}
M_{A} \\
M_{B}
\end{array}\right\} \text { (in Y-X, Z-X plane) } \\
\left\{\begin{array}{l}
\theta_{\mathrm{A}} \\
\theta_{\mathrm{B}} \\
\delta_{\mathrm{x}}
\end{array}\right\} & =\left[f_{p}\right]\left\{\begin{array}{l}
M_{A} \\
M_{B} \\
N_{x}
\end{array}\right\} \text { (at end A, B) }
\end{aligned}
$$

Where, $\left[f_{p}\right]$ is the flexural stiffness matrix of the nonlinear bending spring.

$$
\left\{\begin{array}{l}
\eta_{A} \\
\eta_{B}
\end{array}\right\}=\left[\begin{array}{ll}
1 / K_{S} l & 1 / K_{S} l \\
1 / K_{S} l & 1 / K_{S} l
\end{array}\right]\left\{\begin{array}{l}
M_{A} \\
M_{B}
\end{array}\right\} \text { (in Y-X, Z-X plane) }
$$

Where, $k_{s}$ is the shear stiffness of the nonlinear shear spring.

Shear wall:

$$
\begin{aligned}
& \left\{\begin{array}{l}
\tau_{\mathrm{A}} \\
\tau_{\mathrm{B}}
\end{array}\right\}=\left[\begin{array}{cc}
l / 3 E I & -l / 6 E I \\
-l / 6 E I & l / 3 E I
\end{array}\right]\left\{\begin{array}{l}
M_{A} \\
M_{B}
\end{array}\right\} \text { (in wall panel, side column } 1 \text { and side column 2) } \\
& \left\{\begin{array}{c}
\theta_{y c} \\
\theta_{z 1} \\
\theta_{z 2} \\
\delta_{x c}
\end{array}\right\}=\left[f_{p}\right]\left\{\begin{array}{c}
M_{y c} \\
M_{z 1} \\
M_{z 2} \\
N_{x c}
\end{array}\right\} \text { (at end A, B) }
\end{aligned}
$$

Where, $\left[f_{p}\right]$ is the flexural stiffness matrix of the nonlinear bending spring.

$$
\left\{\begin{array}{c}
\eta_{A} \\
\eta_{B}
\end{array}\right\}=\left[\begin{array}{ll}
1 / K_{S} l & 1 / K_{S} l \\
1 / K_{S} l & 1 / K_{S} l
\end{array}\right]\left\{\begin{array}{l}
M_{A} \\
M_{B}
\end{array}\right\} \text { (in wall panel, side column } 1 \text { and side column 2) }
$$

Where, $k_{s}$ is the shear stiffness of the nonlinear shear spring.

The hysteresis model of a nonlinear bending spring is defined as the moment-rotation relationship under the anti-symmetry loading in Fig. 9. The initial stiffness of the nonlinear spring is supposed to be infinite, however, in numerical calculation, a large enough value is used for the stiffness.

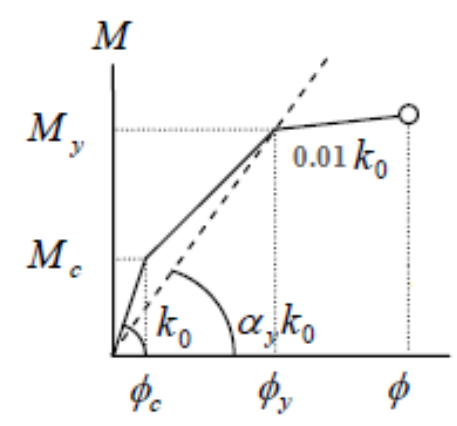

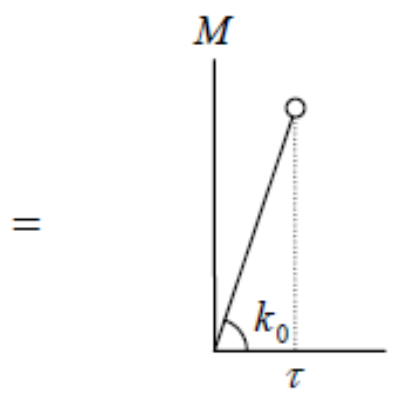

Elastic element

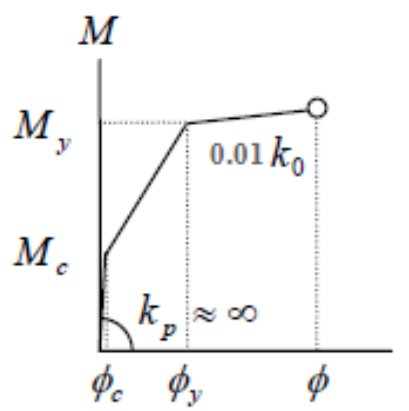

Nonlinear bending spring

Fig. 9 Moment-rotation Relationship at Bending Spring 
The break points of hysteresis model are defined as the following,

Beam:

Where,

$$
\begin{array}{ll}
M_{c 1}=0.56 \sqrt{\sigma_{B}} Z_{e 1}, Z_{e 1}=I_{e} / g & \text { when tension in bottom main rebars } \\
M_{c 2}=0.56 \sqrt{\sigma_{B}} Z_{e 2}, Z_{e 2}=I_{e} /(D-g) & \text { when tension in upper main rebars } \\
M_{y 1}=0.9 a_{1} \sigma_{y}\left(D-d_{1}\right) & \text { when tension in bottom main rebars } \\
M_{y 2}=0.9 a_{2} \sigma_{y}\left(D-d_{2}\right)+0.9 a_{s} \sigma_{y}(D-t / 2) & \text { when tension in upper main rebars } \\
\alpha_{y}=\left(0.043+1.63 n p_{t}+0.043 a / D\right)(d / D)^{2}, a / D \leq 2 & \\
\alpha_{y}=(-0.0836+0.159 a / D)(d / D)^{2}, a / D>2 & \\
\emptyset_{y}=\left(1 / \alpha_{y}-1\right) M_{y} / k_{0} &
\end{array}
$$

$\sigma_{B} \quad$ Compression strength of concrete

$Z_{e 1}, Z_{e 2} \quad$ Section modulus

$\sigma_{y} \quad$ Strength of rebar

$p_{t} \quad$ Tensile reinforcement ratio

$$
\begin{array}{ll}
p_{t}=a_{1} /(B D) & \text { when tension in bottom main rebars } \\
p_{t}=\left(a_{2}+a_{s}\right) /(B D) & \text { when tension in upper main rebars }
\end{array}
$$

$a / D \quad \approx$ Shear span-to-depth ratio $(=l / 2 D)$

$d \quad d=D-d_{1} \quad$ when tension in bottom main rebars

$d \quad d=D-d_{2} \quad$ when tension in upper main rebars

Column:

Where,

$$
\begin{aligned}
& M_{c}=0.56 \sqrt{\sigma_{B}} Z_{e}+N D / 6 \\
& M_{y}=0.8 a_{t} \sigma_{y} D+0.5 N_{b} D\left(1-N_{b} / b D \sigma_{B}\right) \\
& N_{b} \approx 0.4 b D \sigma_{B} \\
& \alpha_{y}=\left(0.043+1.63 n p_{t}+0.043 a / D+0.325 \eta_{b}\right)(d / D)^{2}, a / D \leq 2 \\
& \alpha_{y}=\left(-0.0836+0.159 a / D+0.169 \eta_{b}\right)(d / D)^{2}, a / D>2 \\
& \emptyset_{y}=\left(1 / \alpha_{y}-1\right) M_{y} / k_{0}
\end{aligned}
$$

$\sigma_{B} \quad$ Compression strength of concrete

$\sigma_{y} \quad$ Strength of rebar

$p_{t} \quad$ Tensile reinforcement ratio

$$
\begin{array}{ll}
p_{t}=\left(a_{c}+a_{1}\right) /(2 B D) & \text { when tension in bottom main rebars } \\
p_{t}=\left(a_{c}+a_{2}\right) /(2 B D) & \text { when tension in upper main rebars }
\end{array}
$$

$a / D \quad \approx$ Shear span-to-depth ratio $(=l / 2 D)$

$\begin{array}{lll}d & d=D-d_{1} & \text { when tension in bottom main rebars } \\ d & d=D-d_{2} & \text { when tension in upper main rebars }\end{array}$

Shear wall:

Where,

$$
\begin{aligned}
& M_{y}=a_{s} \sigma_{y} l_{w}+0.5 a_{w} \sigma_{w y} l_{w}+0.5 N l_{w} \\
& M_{c}=0.3 M_{y} \\
& \alpha_{y}=0.02 \\
& \emptyset_{y}=\left(1 / \alpha_{y}-1\right) M_{y} / k_{0}
\end{aligned}
$$

$a_{s} \quad$ Total area of rebar in the side column

$\sigma_{y} \quad$ Strength of rebar in the side column

$a_{w} \quad$ Total area of vertical rebar in the wall panel

$\sigma_{w y} \quad$ Strength of rebar in the wall panel

$N \quad$ Axial load from the dead load

To consider the difference of the flexural capacity between the positive side and the negative side of 
the element, a degrading tri-linear model shown in Fig. 10 is based on the Takeda Model for the hysteresis model of the bending springs of the element.

$$
\begin{aligned}
& k_{y}=0.01\left(\frac{M_{y}}{\emptyset_{y}}\right) \\
& k_{r}=\left(\frac{M_{y}}{\emptyset_{y}}\right)\left|\frac{\emptyset_{y}}{\emptyset_{m}}\right|^{\alpha} \\
& k_{y}=\left(\frac{M_{m}}{\emptyset_{m}-\emptyset_{x}}\right)\left|\frac{\phi_{y}}{\emptyset_{m}}\right|^{\beta}
\end{aligned}
$$
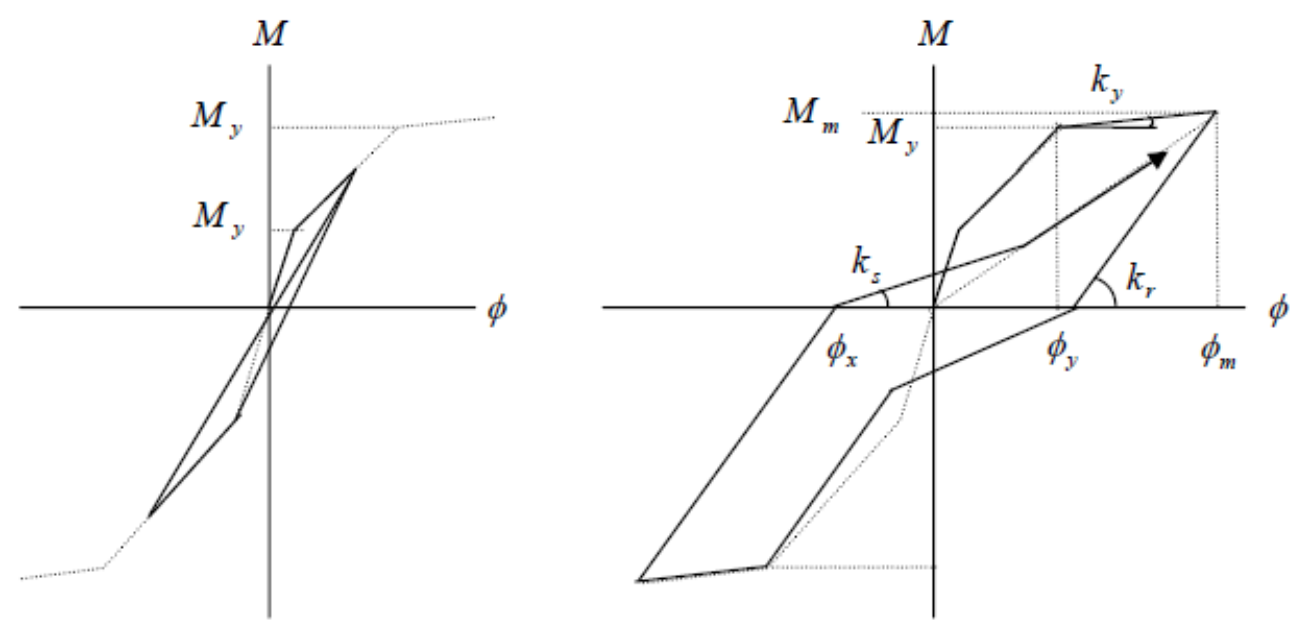

Fig. 10 Degrading Tri-linear Model

Hysteresis model of nonlinear shear spring is defined as the shear force-shear rotation relationship using an origin-oriented poly-linear model as shown in Fig. 11.
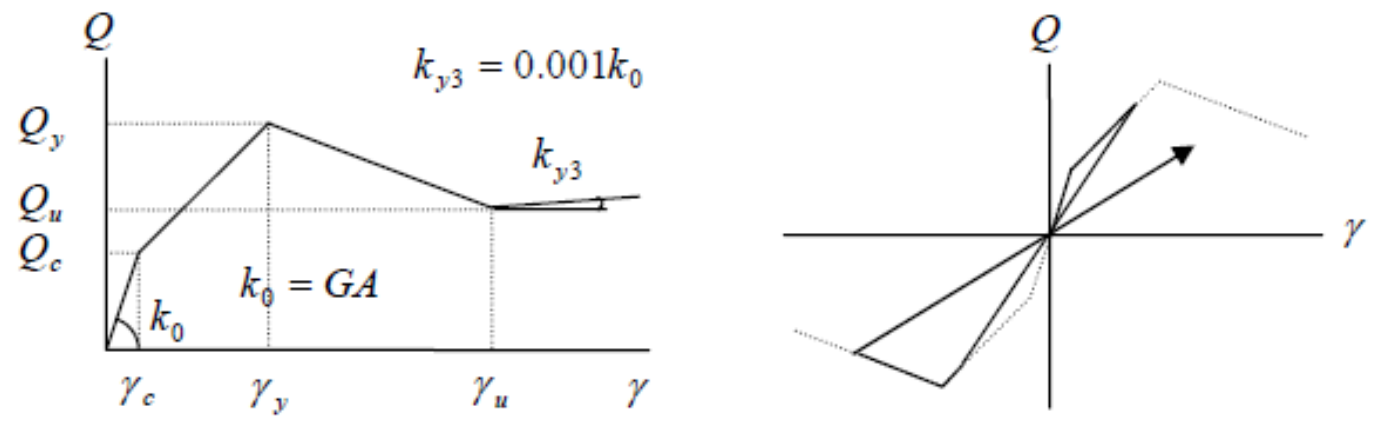

Fig. 11 Force-deformation Relationship of Shear Spring

The break points of hysteresis model are defined as the following,

Beam:

$$
\begin{aligned}
& Q_{y}=\left\{\frac{0.053 p_{t}^{0.23}\left(\sigma_{B}+18\right)}{\frac{M}{Q D}+0.12}+0.85 \sqrt{p_{w} \sigma_{w y}}\right\} b j \\
& Q_{c}=Q_{y} / 3 \quad Q_{u}=Q_{c} \quad \gamma_{c}=Q_{c} / G A \quad \gamma_{y}=1 / 250 \quad \gamma_{u}=1 / 100
\end{aligned}
$$


Where,
$p_{t}$
Tensile reinforcement ratio
$\sigma_{B}$
Compression strength of concrete
$p_{w}$
Shear reinforcement ratio
$\sigma_{w y}$
Strength of shear reinforcement
$j$
Distance between the centers of stress in the section $(=7 d / 8)$

Column:

$$
\begin{aligned}
& Q_{y}=\left\{\frac{0.053 p_{t}^{0.23}\left(\sigma_{B}+18\right)}{\frac{M}{Q D}+0.12}+0.85 \sqrt{p_{w} \sigma_{w y}}+0.1 \sigma_{0}\right\} b j \\
& Q_{c}=Q_{y} / 3 \quad Q_{u}=Q_{c} \quad \gamma_{c}=Q_{c} / G A \quad \gamma_{y}=1 / 250 \quad \gamma_{u}=1 / 100
\end{aligned}
$$

Where,
$p_{t}$
Tensile reinforcement ratio
$\sigma_{B}$
Compression strength of concrete
$M / Q D$
$\approx$ Shear span-to-depth $\operatorname{ratio}(=l / 2 D)$
$p_{w}$
$\sigma_{w y}$
Shear reinforcement ratio
$\sigma_{0} \quad$ Axial stress of the column
Strength of shear reinforcement
$j \quad$ Distance between the centers of stress in the section $(=7 d / 8)$

Shear wall:

Where,

$$
\begin{aligned}
& Q_{y}=\left\{\frac{0.053 p_{t}^{0.23}\left(\sigma_{B}+18\right)}{\frac{M}{Q D}+0.12}+0.85 \sqrt{p_{w} \sigma_{w y}}+0.1 \sigma_{0}\right\} b j \\
& Q_{c}=Q_{y} / 3 \quad Q_{u}=Q_{c} \quad \gamma_{c}=Q_{c} / G A \quad \gamma_{y}=1 / 250 \quad \gamma_{u}=1 / 100
\end{aligned}
$$
$p_{t}$
Tensile reinforcement ratio
$\sigma_{B}$
Compression strength of concrete
$M / Q D$
$\approx$ Shear span-to-depth ratio $(=l / 2 D)$
$p_{w}$
Shear reinforcement ratio
$\sigma_{w y}$
Strength of shear reinforcement
$\sigma_{0}$
Axial stress of the column
$j$
Distance between the centers of stress in the section $(=7 d / 8)$

The stiffness matrix of the flexible floor is considered using a two dimensional isoparametric element as shown in Fig. 12.

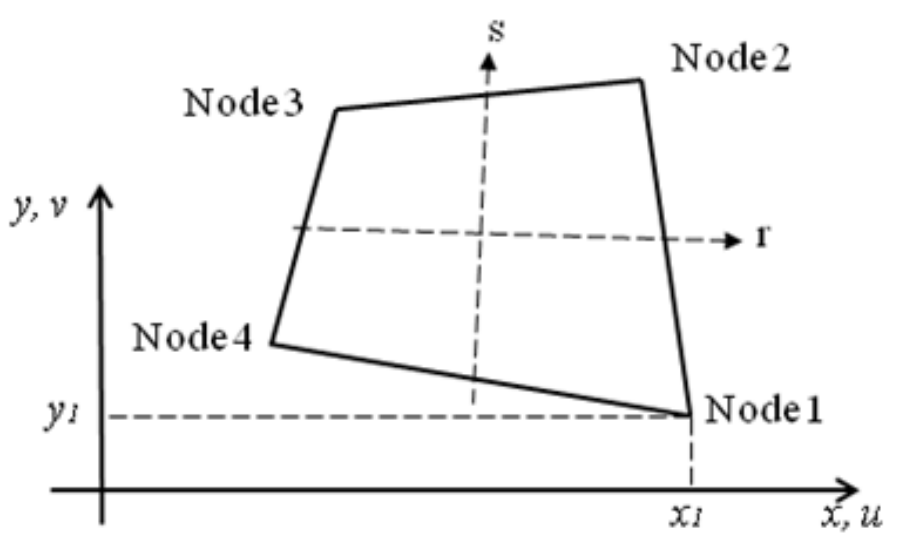

Fig. 12 4-nodes Isoparametric Element 
The model of the whole structure is shown in Fig. 13. The linear soil spring model determined by vibration test is used to the simulation. In this model, each element is modeled by the analytic model shown in the last section.

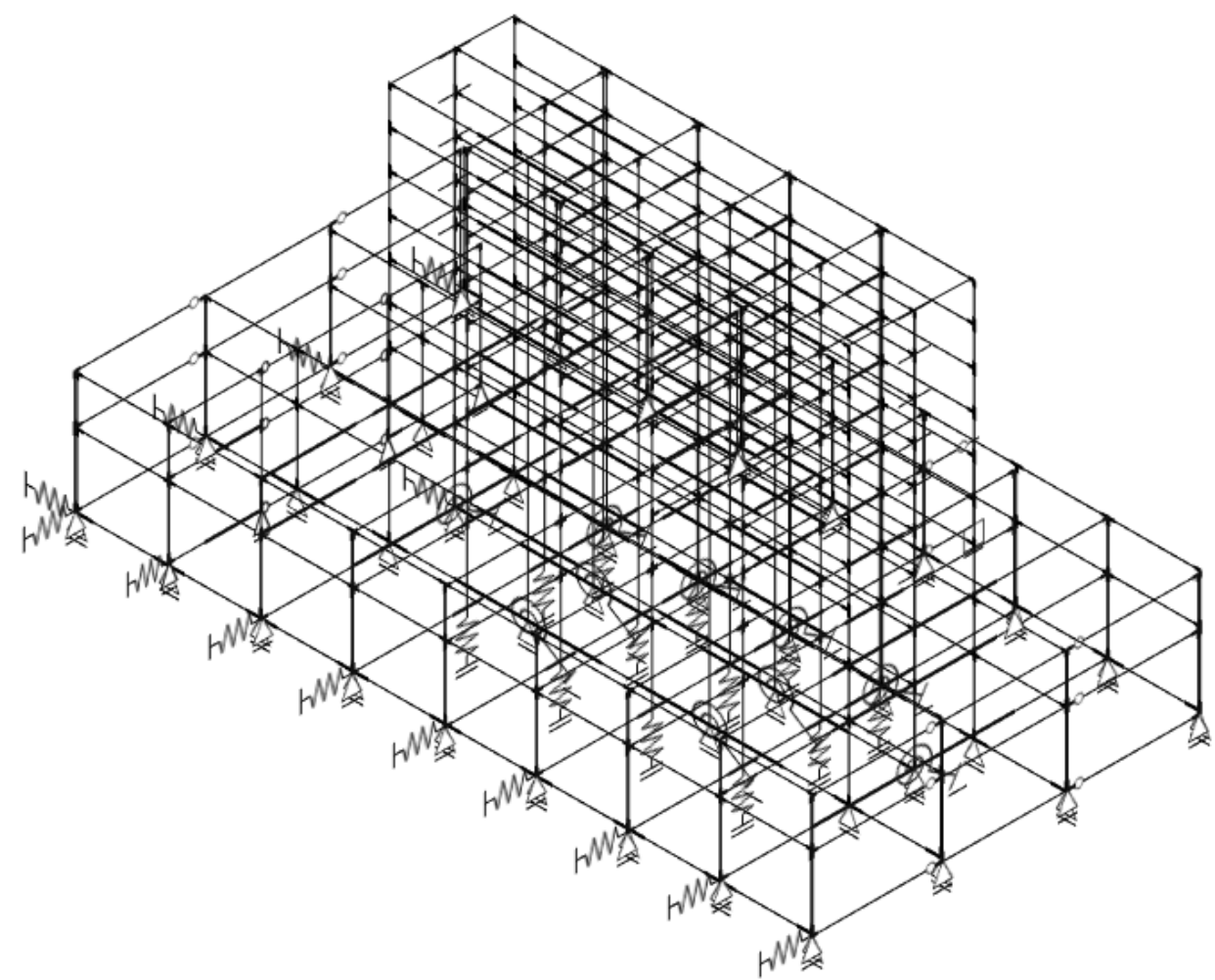

Fig. 13 Model of Frame Structure

Considering the general frame model analysis, the rotational inertia of the node is negligible. The balance equation of the model is defined as,

$$
\left\{\begin{array}{l}
F \\
0
\end{array}\right\}=\left[\begin{array}{ll}
K_{11} & K_{12} \\
K_{21} & K_{22}
\end{array}\right]\left\{\begin{array}{c}
x \\
\theta_{n}
\end{array}\right\}
$$

The force vector of the node is 0 , therefore,

$$
F=\left(K_{11}-K_{12} K_{22}^{-1} K_{21}\right) x
$$

The reduced stiffness matrix is,

$$
K=K_{11}-K_{12} K_{22}^{-1} K_{21}
$$

Finally, three-dimensional equations of motion is,

$$
\left[\begin{array}{lll}
M & & \\
& M & \\
& & I
\end{array}\right]\left\{\begin{array}{l}
\ddot{x} \\
\ddot{y} \\
\ddot{\theta}
\end{array}\right\}+\left[\begin{array}{llll}
\ddots & & \\
& C & \\
& & \ddots
\end{array}\right]\left\{\begin{array}{l}
\dot{x} \\
\dot{y} \\
\dot{\theta}
\end{array}\right\}+\left[\begin{array}{ccc}
K_{x x} & 0 & K_{x \theta} \\
0 & K_{y y} & K_{y \theta} \\
K_{\theta x} & K_{\theta y} & K_{\theta \theta}
\end{array}\right]\left\{\begin{array}{l}
x \\
y \\
\theta
\end{array}\right\}=-\left\{\begin{array}{l}
F_{x} \\
F_{y} \\
F_{\theta}
\end{array}\right\}
$$

The damping matrix is defined as a classical Rayleigh damping ${ }^{9)}$. Where, the $1^{\text {st }}$ characteristic frequency is $1.61 \mathrm{~Hz}$ and the $2^{\text {nd }}$ characteristic frequency is $2.95 \mathrm{~Hz}$ in the two directions depending on 
the micro tremor observations. And both the Rayleigh damping factors of them are 0.03 .

\section{Input Motion and Soil-structure Interaction}

The sway springs and the rocking springs are connected with the foundation of the building. The soil-structure interaction is considered for the simulation analysis. But in fact, the ground input motion was not observed in the 2011 Great East Japan Earthquake. Only the records at the $1^{\text {st }}$ floor and the $9^{\text {th }}$ floor were observed. Therefore, the ground input motion should be calculated from the records on $1^{\text {st }}$ floor. Here, a simplification model is used as shown in Fig. 14.

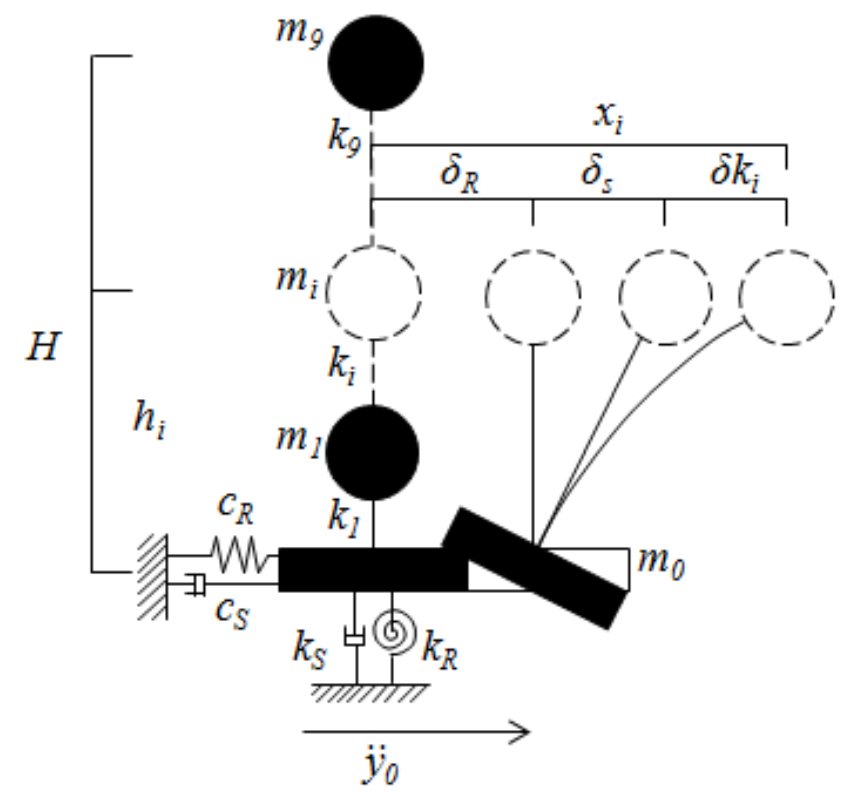

Fig. 14 Simplification Model of Structure

The equation of the motion in the one direction is defined as equation 19. Therefore, the earthquake record observed at the $1^{\text {st }}$ floor can substitute for the input motion in the simulation. As the foundation of the building is not embedded, the effect of frequency depending damping is not significant. The sway stiffness and the rocking stiffness which quoted from the vibration test in 2001 shown in Table 5 are used to simulate. An exciter was used in the test to make a vibration. Some sensors were installed in each floor. The displacement and rotation data were recorded during the test. The calculation methods of sway stiffness and the rocking stiffness are shown in equation 20 and 21 . Where, $u_{i}, \theta_{i}$ are displacement and rotation angle of each floor. $h_{f}$ is height of the exciter used in test.

$$
\begin{gathered}
{\left[M^{\prime}, M\{P\}-\left\{m_{s}\right\}\right]\left\{\begin{array}{c}
\ddot{x}_{9}(t) \\
\vdots \\
\ddot{x}_{1}(t) \\
\ddot{y}_{0}(t) \\
\ddot{x}_{r}(t)
\end{array}\right\}+\left[C,\left\{c_{s}\right\}\right]\left\{\begin{array}{c}
\dot{x}_{9}(t) \\
\vdots \\
\dot{x}_{1}(t) \\
\dot{y}_{0}(t) \\
\dot{x}_{r}(t)
\end{array}\right\}+\left[K,\left\{k_{s}\right\}\right]\left\{\begin{array}{c}
x_{9}(t) \\
\vdots \\
x_{1}(t) \\
y_{0}(t) \\
x_{r}(t)
\end{array}\right\}} \\
=-\left\{m_{s}\right\}\left(\ddot{y}_{0}(t)+\ddot{x}_{s}(t)\right)-\left\{c_{s}\right\}\left(\dot{y}_{0}(t)+\dot{x}_{s}(t)\right)-\left\{k_{s}\right\}\left(y_{0}(t)+x_{s}(t)^{10)}\right. \\
K_{s}=Q / u_{0}=\left(\omega^{2} \sum_{i=0}^{9} m_{i} u_{i}+1\right) / u_{0}
\end{gathered}
$$




$$
K_{r}=M /_{\theta_{0}}=\left(\omega^{2} \sum_{i=0}^{9} I_{i} \theta_{i}+\omega^{2} \sum_{i=0}^{9} m_{i} u_{i} h_{i}+h_{f}\right) / \theta_{0}
$$

Table 5 Sway Stiffness and Rocking Stiffness of Foundation

\begin{tabular}{|c|c|c|}
\hline Direction & Sway Stiffness & Rocking Stiffness \\
\hline EW & $1.58 \times 10^{7} \mathrm{~N} / \mathrm{m}$ & $1.28 \times 10^{10} \mathrm{Nm} / \mathrm{rad}$ \\
\hline $\mathrm{NS}$ & $1.41 \times 10^{7} \mathrm{~N} / \mathrm{m}$ & $4.42 \times 10^{9} \mathrm{Nm} / \mathrm{rad}$ \\
\hline
\end{tabular}

Fig. 15 shows the frequency response function of the observation record at the $1^{\text {st }}$ floor and the ground input motion. The observation record at the $1^{\text {st }}$ floor is a little difference with the ground input motion in the NS direction. And the observation record at the $1^{\text {st }}$ floor is almost the same as the ground input motion in the EW direction. The $1^{\text {st }}$ frequency of super structure is shown as the valley of the curve, and it is nearly agreed with the predominant period by the micro tremor observations.
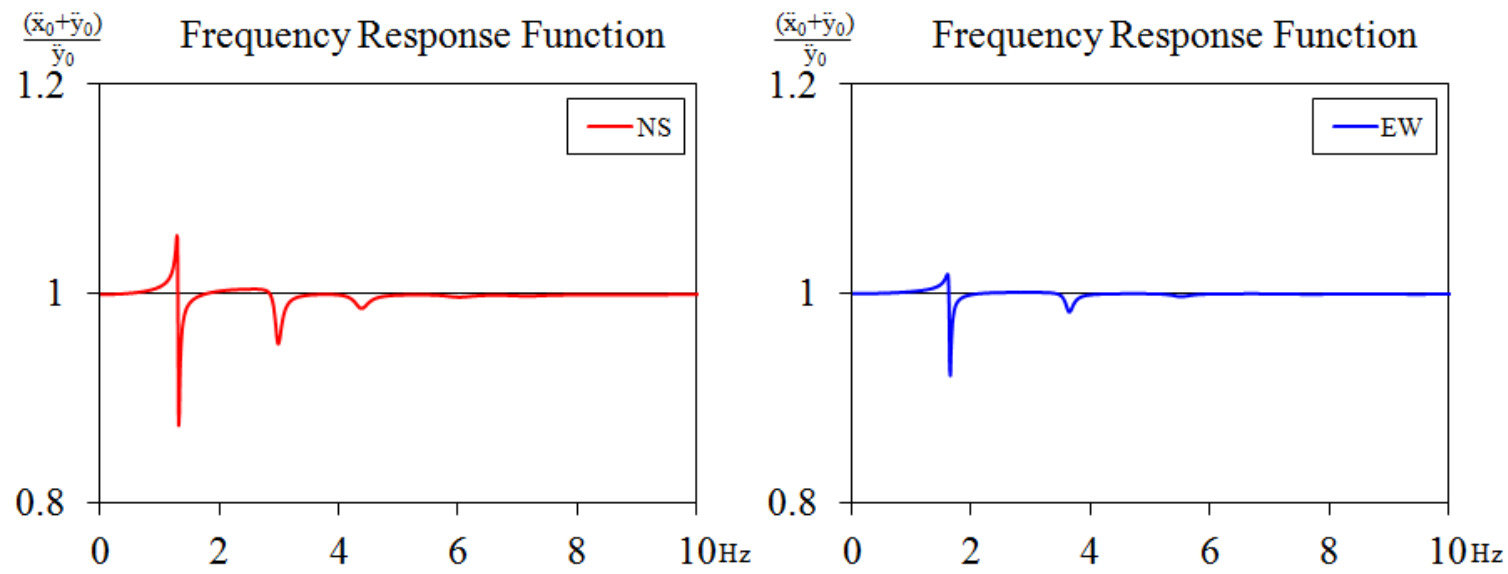

Fig. 15 Frequency Response Function

\section{Condition of Simulation}

In this simulation, the stiffness reduction factors shown in Table 4 are used in the first model which called Model A. The comparison between the observed response accelerations and the simulated response accelerations is shown in Fig. 16.

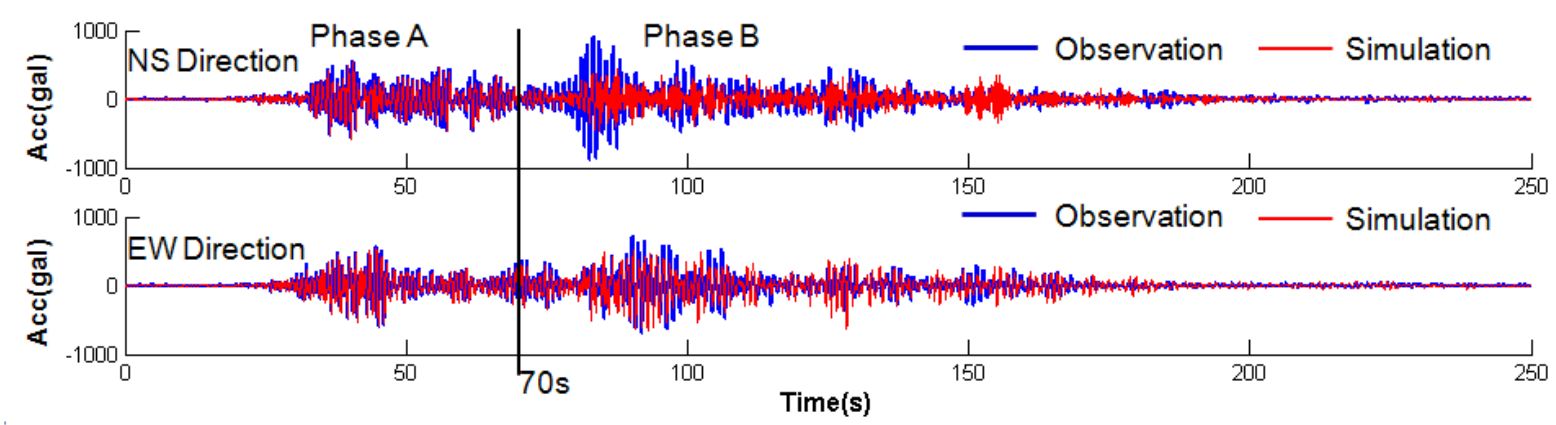

Fig. 16 Comparisons of the Observed and Simulated Accelerations Using Model A at the $9^{\text {th }}$ Floor (Top: NS direction, Bottom: EW direction) 
The simulated accelerations agree with the records before 70s (Phase A). But after 70s (Phase B), the simulated accelerations become smaller than the records, especially in the NS direction. It means that the building was severely damaged during the earthquake and the properties of constituent structural elements might be changed.

Therefore, a new model called Model B is considered for Phase B. As the building was severely damaged during the earthquake, the dynamic hysteresis characteristics are analyzed from the observation records, and the fact that the stiffness of the elements was reduced during the earthquake has been proved ${ }^{12)}$. For this reason, the new stiffness reduction factors are calculated according to the dynamic hysteresis characteristics ${ }^{12)}$ and the crack pattern of the building ${ }^{13)}$. The stiffness of the elements which was cracked in the earthquake is reduced and the strength of the elements is reduced automatically according to the dynamic characteristics. The stiffness reduction factors for new model are shown in Table 6 . Because there are too many elements at each floor, the simplification of table 6 such as $0.40 \sim 0.48$ means that the minimum stiffness reduction factor is 0.40 and the maximum one is 0.48 , which according by the plane crack pattern of each floor ${ }^{13)}$.

Table 6 Stiffness Reduction Factor for the Model B

\begin{tabular}{|c|c|c|c|c|c|c|}
\hline \multirow{2}{*}{ Floor } & \multicolumn{2}{|c|}{ Beam \& Column } & \multicolumn{2}{c|}{ Shear Wall(core) } & \multicolumn{2}{c|}{ Shear Wall(gable) } \\
\cline { 2 - 7 } & EW & NS & EW & NS & E & W \\
\hline RF & $0.40 \sim 0.48$ & $0.50 \sim 0.59$ & & \multicolumn{3}{|c|}{} \\
\hline 9F & $0.37 \sim 0.48$ & $0.45 \sim 0.59$ & 0.37 & $0.40 \sim 0.50$ & 0.65 & 0.75 \\
\hline $8 \mathrm{~F}$ & $0.37 \sim 0.48$ & $0.45 \sim 0.59$ & $0.33 \sim 0.37$ & $0.40 \sim 0.50$ & 0.75 & 0.75 \\
\hline 7F & $0.37 \sim 0.48$ & $0.45 \sim 0.50$ & $0.33 \sim 0.37$ & $0.35 \sim 0.50$ & 0.75 & 0.75 \\
\hline $6 \mathrm{~F}$ & $0.27 \sim 0.35$ & $0.35 \sim 0.50$ & $0.3 \sim 0.37$ & $0.25 \sim 0.40$ & 0.65 & 0.60 \\
\hline 5F & $0.25 \sim 0.35$ & $0.35 \sim 0.50$ & $0.33 \sim 0.41$ & $0.25 \sim 0.40$ & 0.65 & 0.60 \\
\hline 4F & $0.25 \sim 0.35$ & $0.25 \sim 0.40$ & $0.33 \sim 0.41$ & $0.25 \sim 0.40$ & 0.65 & 0.55 \\
\hline 3F & $0.25 \sim 0.35$ & $0.25 \sim 0.40$ & 0.41 & $0.25 \sim 0.40$ & 0.65 & 0.50 \\
\hline 2F & $0.55 \sim 0.62$ & $0.45 \sim 0.61$ & $0.50 \sim 0.60$ & $0.40 \sim 0.61$ & 0.55 & 0.65 \\
\hline 1F & $0.60 \sim 0.62$ & $0.45 \sim 0.62$ & $0.55 \sim 0.68$ & $0.45 \sim 0.61$ & 0.55 & 0.60 \\
\hline
\end{tabular}

These factors are fitting in with the analysis results of the dynamic restoring force characteristic in Phase B from the observation records ${ }^{12}$. Fig. 17 shows the comparisons of the observed and combined simulated response accelerations using Model B in the NS and EW directions at the $9^{\text {th }}$ floor.

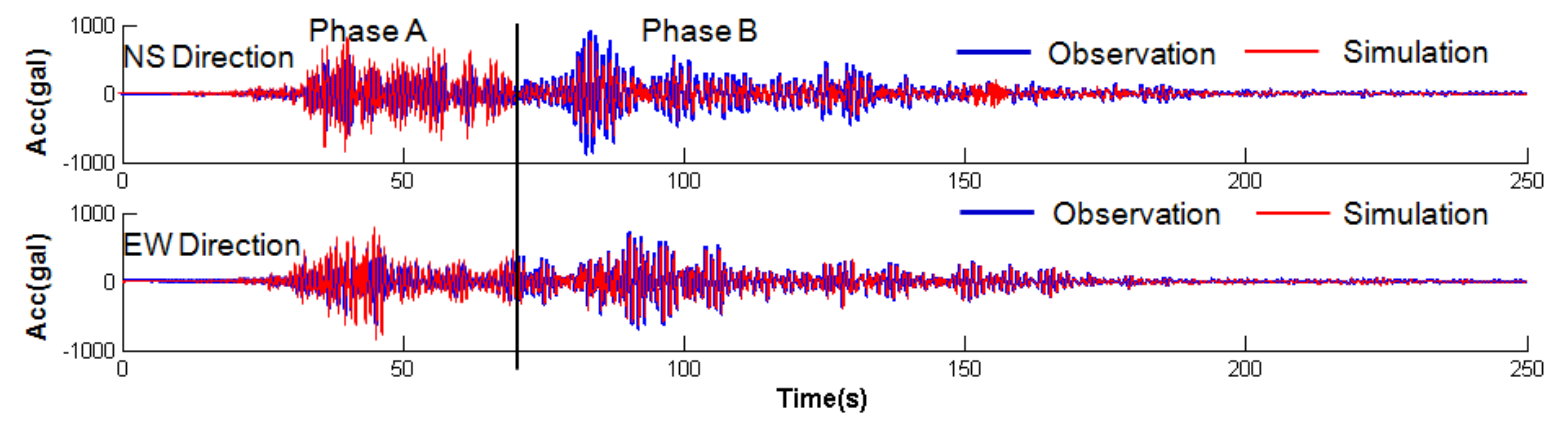

Fig. 17 Comparisons of the Observed and Simulated Accelerations Using Model B at the $9^{\text {th }}$ Floor (Top: NS direction, Bottom: EW direction)

The simulated accelerations almost agree with the records after 70s (Phase B). But before 70s (Phase A), the simulated accelerations become bigger than the records in the two directions. It means that the 
reductions of the stiffness and the strength of the elements are considered in this new model. To agree with both of the phases, a degrading model along with cyclic loading should be used in the simulation. But as the free software STERA 3D is used for simulation, the degrading tri-linear model in the software cannot change and reduce the stiffness and the strength during analysis, the stiffness and the strength of elements are weaker than real ones in Phase B.

Briefly speaking, the stiffness and strength of the elements is reduced during the earthquake, and the single model cannot contain both of the situations of the phase. When Model A is used, the simulation will be smaller than the observation in Phase B. On the contrary, when Model B is used, the simulation will be larger than the observation in Phase A.

\section{Results of Simulation}

Fig. 18 shows the pseudo velocity response spectrum for Phase A and Phase B in the NS and EW directions at the 9th floor. (PA, MA) is the abbreviation for Phase A using Model A. The reduction of stiffness is also confirmed by the calculation of the change of the predominant periods from Fig. 18 . The whole pseudo velocity response spectrum is almost depended on Phase B except the peak of $0.6 \mathrm{~s}$ in the EW direction. In the NS direction, both of the predominant periods are 1.06s, and the value of the pseudo velocity response spectra calculated by the simulation is $659 \mathrm{~cm} / \mathrm{s}$ and the one calculated by the observation is $978 \mathrm{~cm} / \mathrm{s}$. In the EW direction, both of the predominant periods are $1.13 \mathrm{~s}$, and the value of the pseudo velocity response spectra calculated by the simulation is $673 \mathrm{~cm} / \mathrm{s}$ and the one calculated by the observation is $739 \mathrm{~cm} / \mathrm{s}$. By the way, the predominant period of the transfer function $\left(9^{\text {th }}\right.$ floor $/ 1^{\text {st }}$ floor $)$ in the NS direction is $1.28 \mathrm{~s}$ and the one in the EW direction is $1.13 \mathrm{~s}$.
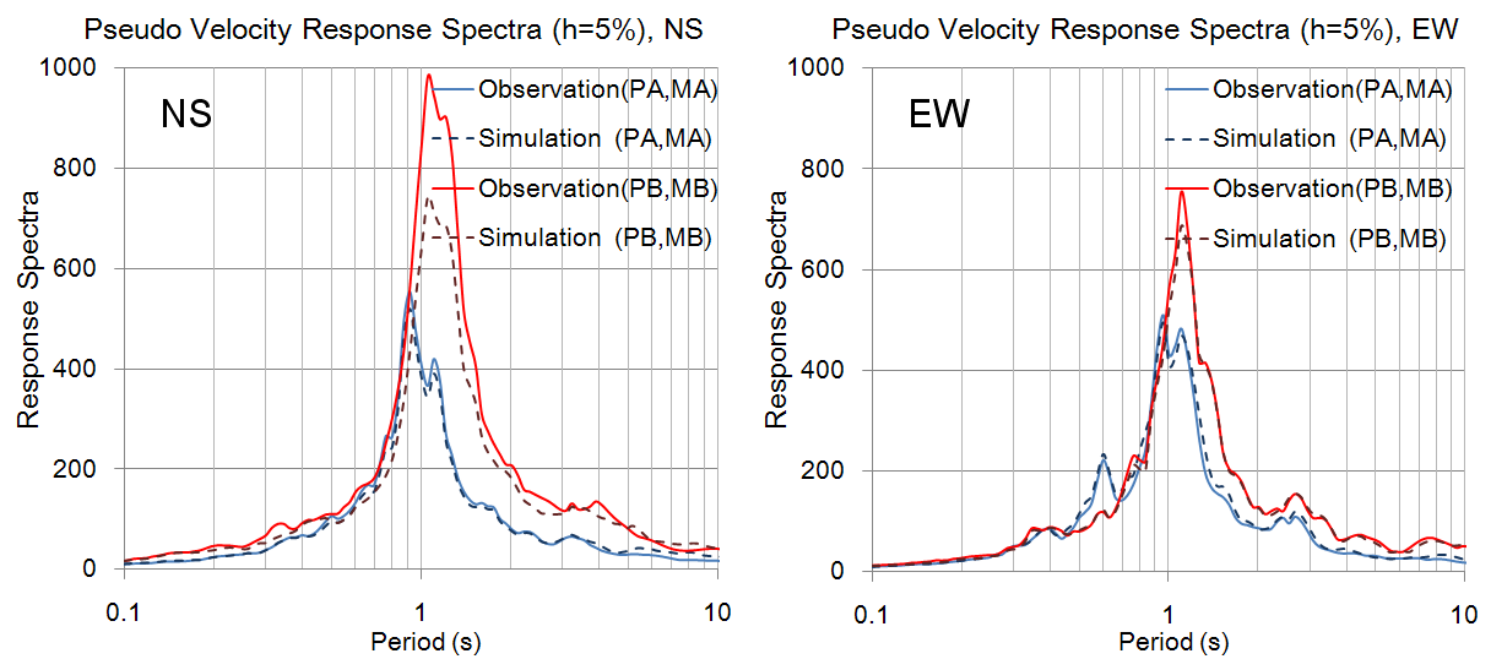

Fig. 18 Pseudo Velocity Response Spectrum of NS and EW Directions

The pseudo velocity response spectra calculated by the simulation agree with the one calculated by the observation in the EW direction. But in the NS direction, the value of the response spectra simulated is smaller than the observation, although the predominant period is the same. Here, the partial uplift phenomenon at the $3^{\text {rd }}$ floor suggested by Tsamba and Motosaka ${ }^{11)}$ and Motosaka et al. ${ }^{12)}$ is one of the important reasons. Fig. 19 shows the mechanism of the partial uplift phenomenon between the $2^{\text {nd }}$ floor and the $3^{\text {rd }}$ floor. Because this phenomenon is not considered in this analysis, the disparity between the simulation and observation in the NS direction is shown in Fig. 18.

Fig. 20 shows the maximum acceleration of the each floor. The value increases rapidly from the $4^{\text {th }}$ floor. It consists with the fact that the damage above the $3^{\text {rd }}$ floor is rather more severe than the low floors. 


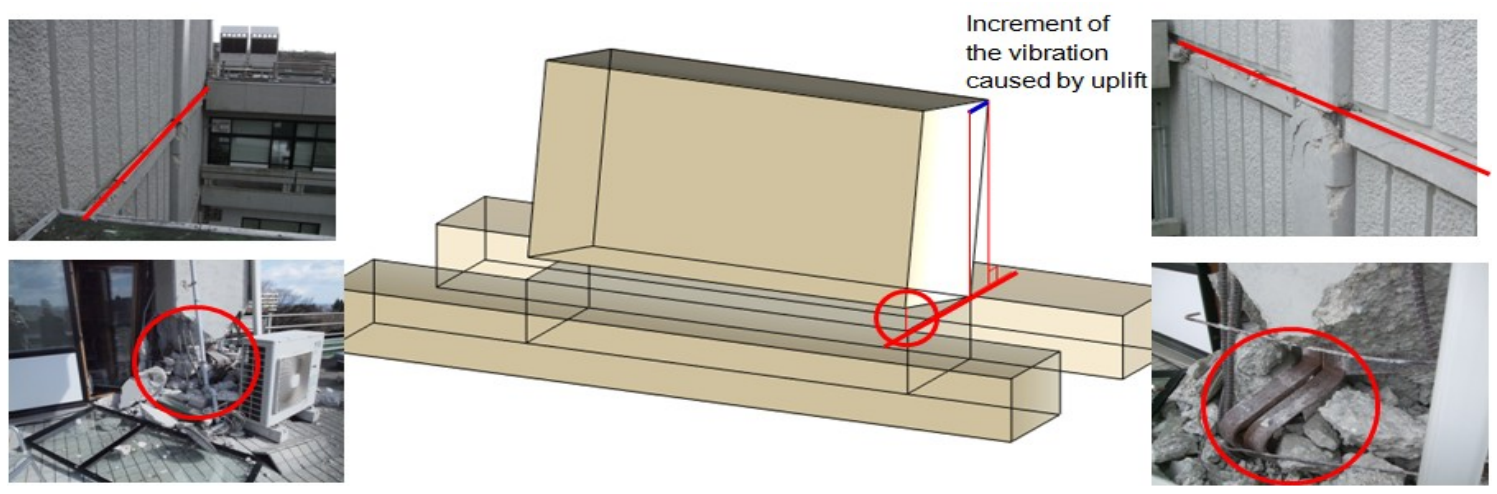

Fig. 19 Mechanism of Partial Uplift Phenomenon
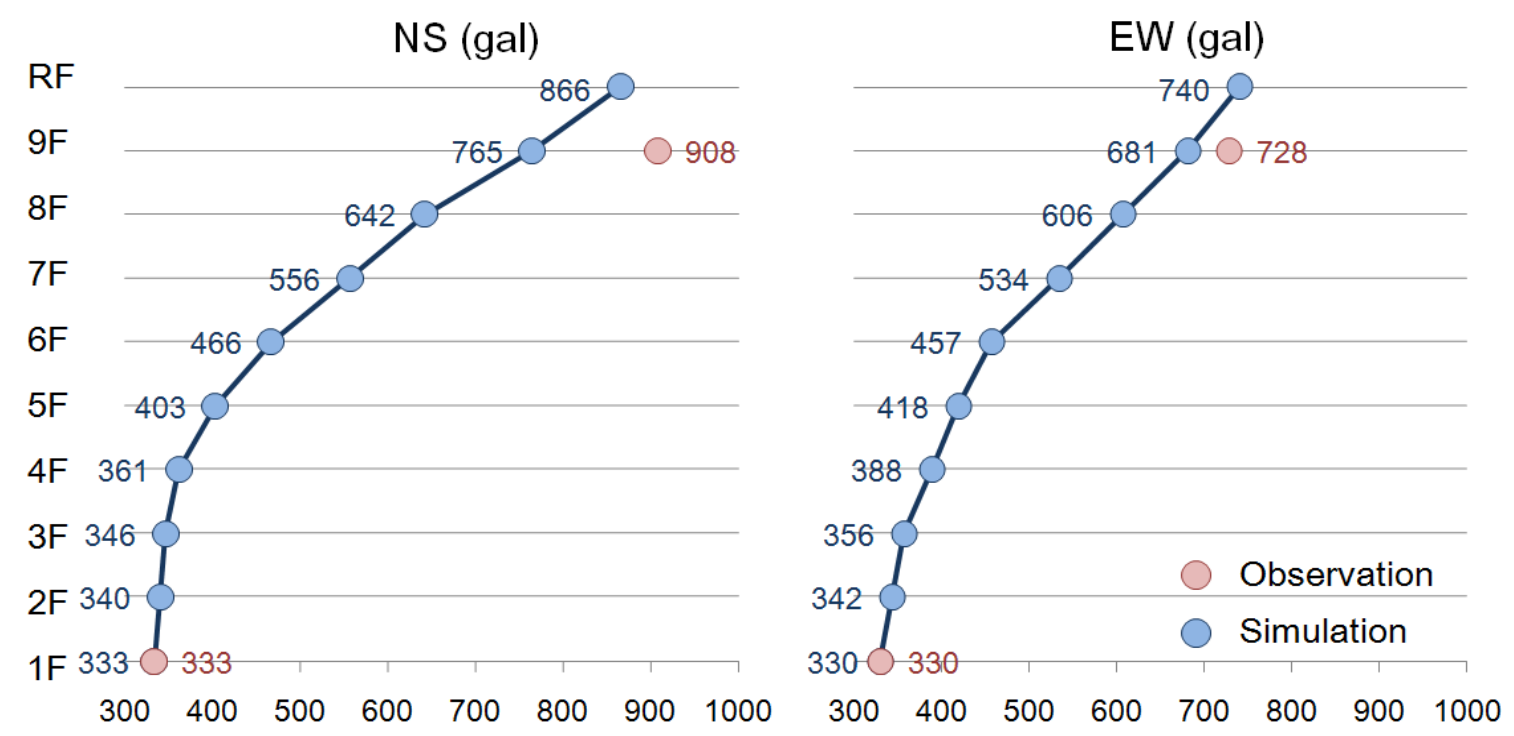

Fig. 20 Maximum Acceleration of Each Floor

\section{CONCLUSIONS}

The process of damage of the 9-story SRC building in Sendai during the 2011 Great East Japan Earthquake is simulated with the elastic plastic frame model using STERA 3D. The acceleration data are compared with the observed records at the $9^{\text {th }}$ floor. In the simulation analysis, the stiffness reduction of each element is important. During the earthquake, the building was severely damaged and the properties of constituent structural elements were changed. The stiffness and the strength of elements were both reduced during the earthquake.

In this study, only the degrading tri-linear model, which is applicable in STERA 3D is applied to the simulation analysis. It is found through the analyses that a degrading model along with cyclic loading should be considered in future research. For better correlation between simulated response and observed data in the NS (Transverse) direction, consideration of the suggested partial uplift phenomenon at the $3^{\text {rd }}$ floor during this earthquake would be needed in future study.

\section{ACKNOWLEDGMENT}

The earthquake observation record used in this paper is provided by BRI. The authors thank Dr. 
Toshihede KASHIMA and the related persons. The free software STERA 3D is used for some calculation in this study. Thanks to Dr. Taiki SAITO, IISEE, who developed and provided this software.

\section{REFERENCES}

1) Masato Motosaka, Kazuya Mitsuji, Shoko Tanaka, Toshihide Kashima, and Susumu Ohno (2011). "Change of Dynamic Characteristics of a Damaged Building Before, During and After the 2011 Off-Pacific Coast Tohoku Earthquake", AIJ Annual Meeting, Structure II, 45-46 (in Japanese)

2) Toshio Shiga, Akenori Shibata, Junichi Shibuya (1973). "Dynamic Properties and Earthquake Response of a 9 Story Reinforced Concrete Building", Fifth World Conference on Earth-quake Engineering, 342 Session 7D

3) TOSHIO SHIGA, AKENORI SHIBATA, JUNICHI SHIBUYA, JUNICHI TAKAHASHI (1981). "Observations of Strong Earthquake Motions and Nonlinear Response Analyses of the Building of Architectural and Civil Engineering Department, Tohoku University", Transactions of the Architectural Institute of Japan (301), 119-129 (in Japanese)

4) Masato MOTOSAKA, Takeshi SATO, Yuu YAMAMOTO (2004). "Amplitude Dependent Dynamic Charac- teristics of an Existing Building", $13^{\text {th }}$ World Conference on Earthquake Engineering, CD-ROM No.1023

5) Tomokazu TATENO, Masato MOTOSAKA (2001). "Vibration Test Using a Centrifugal-Type Vibrator and Simulation Analyses of the Building of Architectural and Civil Engineering Department, Tohoku University", Tohoku Journal of Natural Disaster Science, Vol. 37,175-180 (in Japanese)

6) Masato MOTOSAKA, Tomokazu TATENO, Hiroyuki SUZUKI (2001). "System Identification Based on Vibration Test Using a Centrifugal-Type Vibrator of Existential Building and Control Simulation Analyses”, Architectural Institute of Japan (Tohoku) ,Vol. 64, 65-68 (in Japanese)

7) Taiki Saito, Shu-ichiro Abe, Akenori Shibata (1997). "Seismic Damage Analysis of Reinforced Concrete Buildings Based on Statistics of Structural Lateral Resistance”, Structural Safety, Vol.19, No.1, 141-151

8) Taiki SAITO (2012). "STERA_3D Technical Manual”, International Institute of Seismology and Earthquake Engineering

9) Anil K. Chopra (2001). "Dynamics of Structures: Theory and Applications to Earthquake Engineering", Prentice-Hall, 455-458

10) KIYOSHI MUTO, TADASHI SUGANO, MASAMITSU MIYAMURA, MINORU HANAJIMA, MASATO MOTOSAKA (1980). "Analysis of Strong-motion Accelerograms in Miyagiken-oki Earthquake February 20 and June 12, 1978, Part1: Comparison of Observed Waves at Neighboring Three Buildings", Transactions of the Architectural Institute of Japan (291), 45-52 (in Japanese)

11) Tsamba Tsoggerel, Masato Motosaka (2011). "Investigation of Dynamic Behavior of a Damaged 9-story Building during the 2011 off the Pacific Coast Tohoku Earthquake", 2011-JAEE Annual Meeting, 24-25

12) MOTOSAKA Masato, TSAMBA Tsoggerel, YOSHIDA Kazushi, and MITSUJI Kazuya (2012). "Long-term Monitoring of Amplitude Dependent Dynamic Characteristics of a Damaged Building during the 2011 Tohoku Earthquake", Journal of Japan Association for Earthquake Engineering, Vol.12, No.5, 117-132 (in Japanese)

13) Masaki MAEDA, Hamood Ahmed AL-WASHALI, Kanako TAKAHASHI, and Kazuki SUZUKI(2012), "Damage to Reinforced Concrete School Buildings in Miyagi after the 2011 Great East Japan Earthquake", Proceedings of the International Symposium on Engineering Lessons Learned from the 2011 Great East Japan Earthquake, 1120-1131 


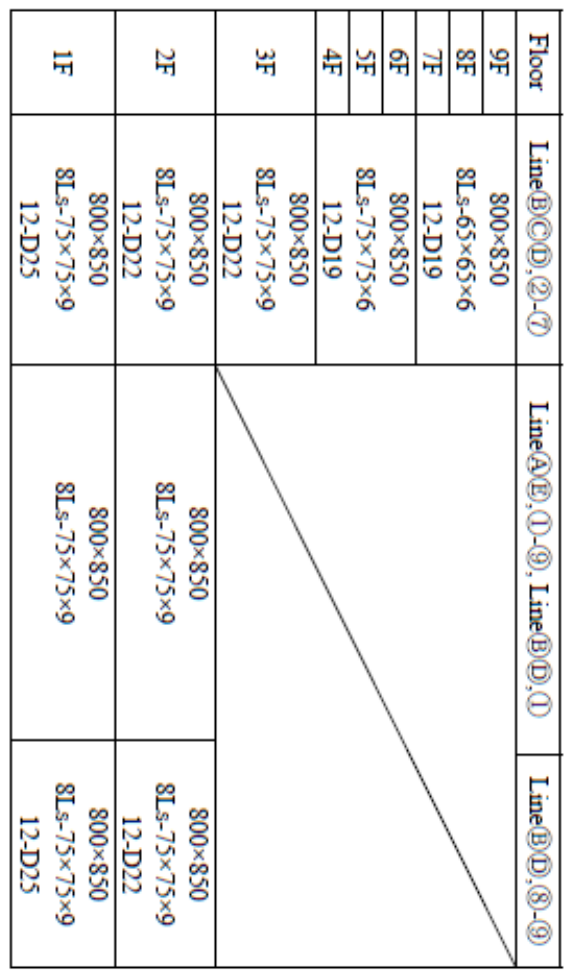

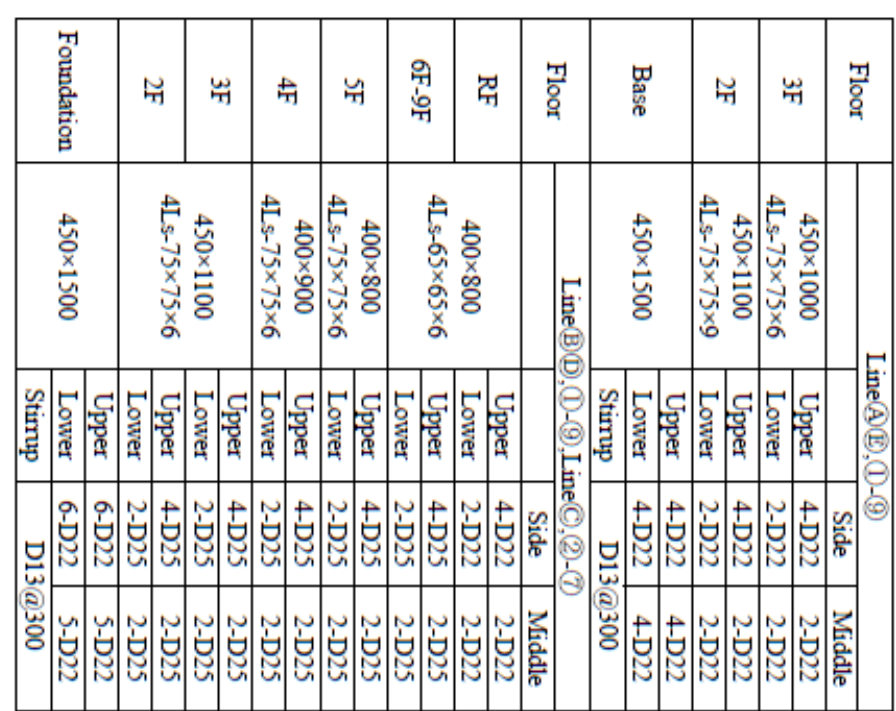

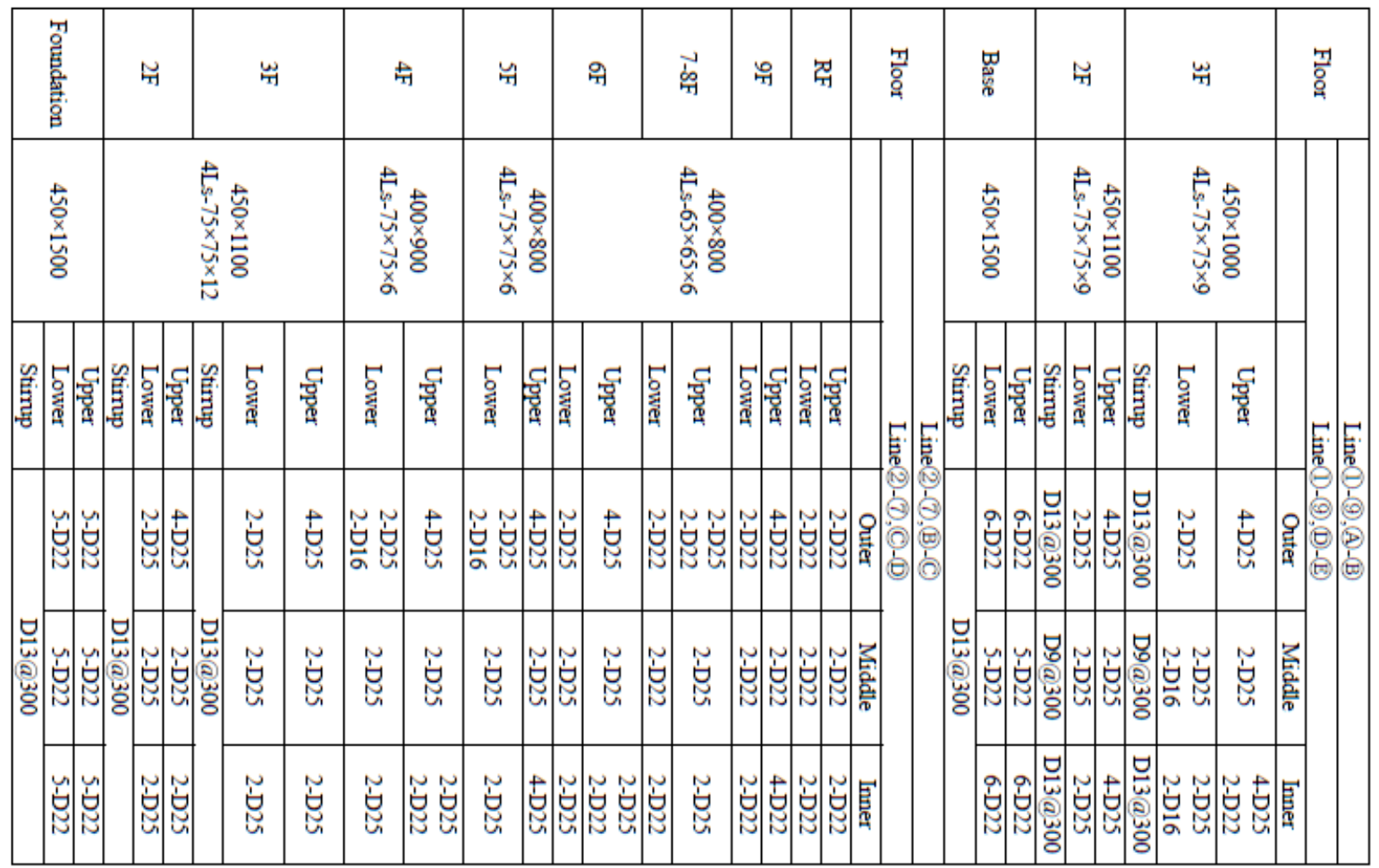

